\title{
LANDSLIDE MAPPING USING MULTTSCALE LIDAR DIGITAL ELEVATION MODELS
}

By

Javed Miandad

A Thesis Submitted in Partial Fulfillment of the Requirements

for the Degree of

Master of Science

in

Geological Engineering

University of Alaska Fairbanks

August 2018

Approved:

Margaret Darrow, Committee Chair

Paul Metz, Committee Member

Ronald Daanen, Committee Member

Michael Hendricks, Committee Member

Margaret Darrow, Chair

Department of Mining and Geological Engineering

Doug Goering, Dean

College of Engineering and Mines

Michael Castellini, Dean of Graduate School 


\begin{abstract}
This study presents a new methodology to identify landslide and landslide susceptible locations in Interior Alaska using only geomorphic properties from light detection and ranging (LiDAR) derivatives (i.e., slope, profile curvature, roughness) and the normalized difference vegetation index (NDVI). The study specifically focused on the effect of different resolutions of LiDAR images in identifying landslide locations. I developed a semi-automated object-oriented image classification approach in ArcGIS 10.5 , and prepared a landslide inventory from visual observation of hillshade images. The multistage workflow included combining derivatives from $1 \mathrm{~m}, 2.5 \mathrm{~m}$, and $5 \mathrm{~m}$ resolution LiDAR, image segmentation, image classification using a support vector machine classifier, and image generalization to clean false positives. I assessed the accuracy of the classifications by generating confusion matrix tables. Analysis of the results indicated that the scale of LiDAR images played an important role in the classification, and the use of NDVI generated better results in identifying landslide and landslide susceptible places. Overall, the LiDAR $5 \mathrm{~m}$ resolution image with NDVI generated the best results with a kappa value of 0.55 and an overall accuracy of $83 \%$. The LiDAR $1 \mathrm{~m}$ resolution image with NDVI generated the highest producer accuracy of $73 \%$ in identifying landslide locations. I produced a combined overlay map by summing the individual classified maps, which was able to delineate landslide objects better than the individual maps. The combined classified map from $1 \mathrm{~m}, 2.5 \mathrm{~m}$, and $5 \mathrm{~m}$ resolution LiDAR with NDVI generated producer accuracies of $60 \%, 80 \%, 86 \%$, and user accuracies of $39 \%, 51 \%, 98 \%$ for landslide, landslide susceptible, and stable locations, respectively, with an overall accuracy of $84 \%$ and a kappa value of 0.58 . The proposed
\end{abstract}


method can be improved by fine-tuning segmented image generation, incorporating other data sets, and developing a standard accuracy assessment technique for objectoriented image analysis. 


\section{Table of Contents}

Page

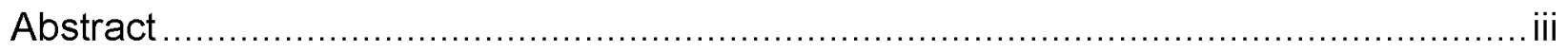

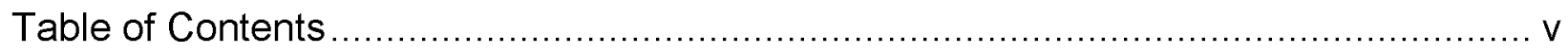

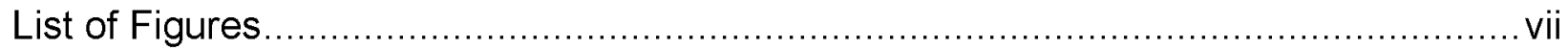

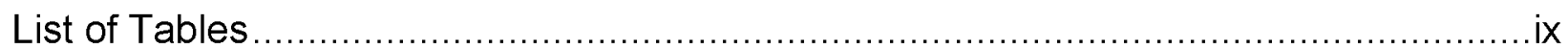

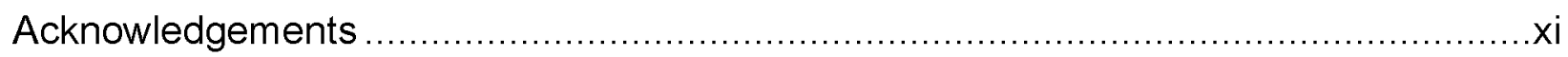

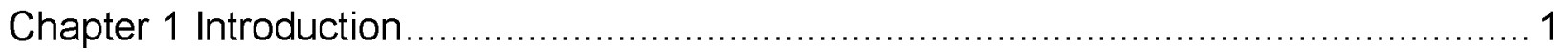

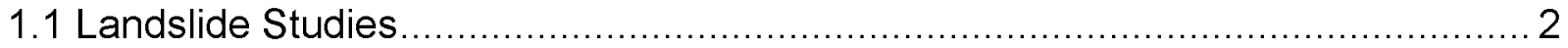

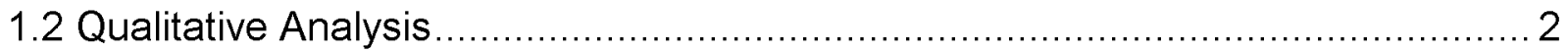

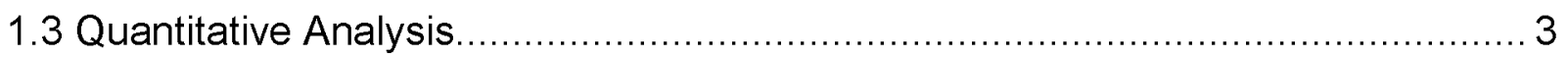

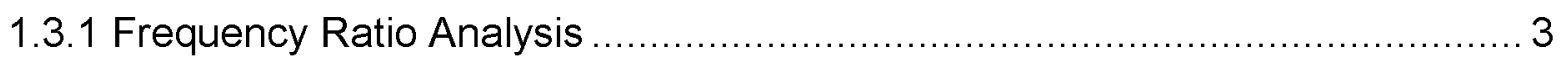

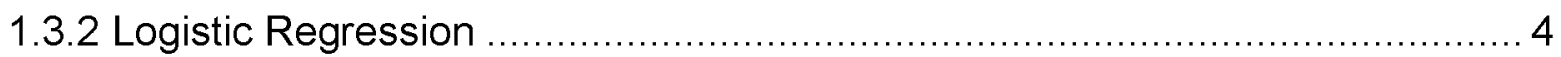

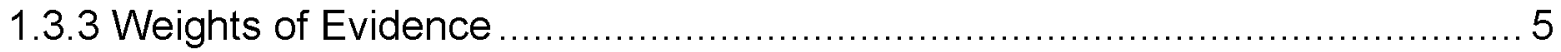

1.3.4 Artificial Neural Networks and Support Vector Machines.......................... 6

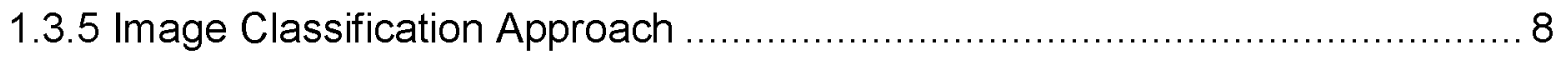

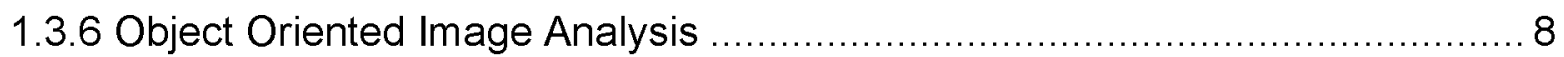

1.4 Goal of This Research and Thesis Organization......................................... 10

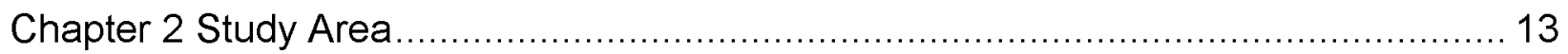

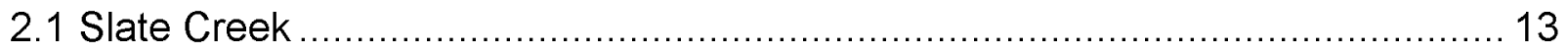




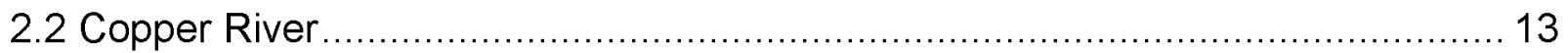

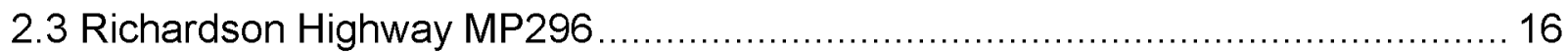

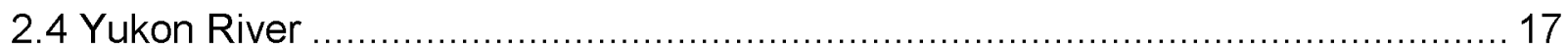

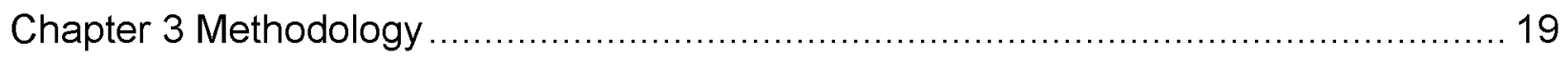

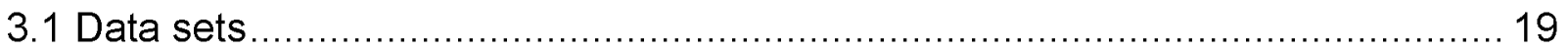

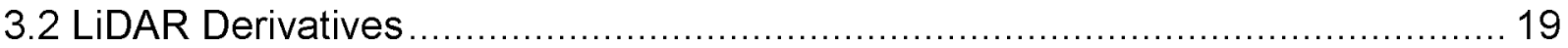

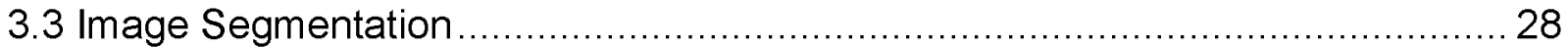

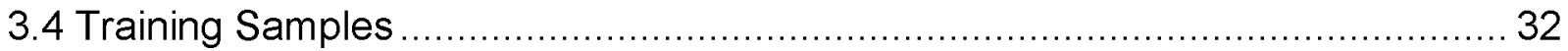

3.5 Support Vector Machine (SVM) Classifier................................................ 32

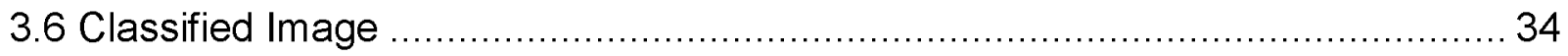

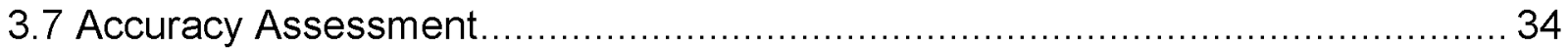

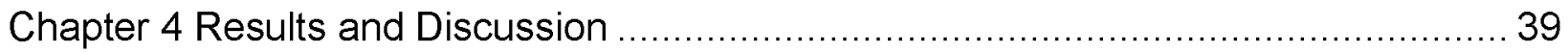

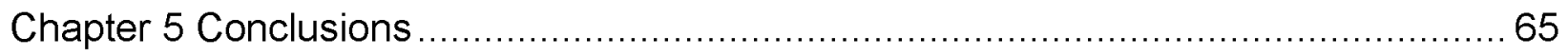

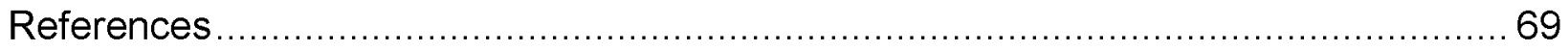




\section{List of Figures}

Page

Figure 2.1: Locations of study sites: Slate Creek, Copper River, Richardson, and Yukon

Figure 2.2: Landslide inventory prepared using visual inspection of LiDAR data.... 15

Figure 3.1: Slope derived from the $1 \mathrm{~m}$ resolution LiDAR digital elevation model 21

Figure 3.2: Profile curvature derived from the $1 \mathrm{~m}$ resolution LiDAR digital elevation

model.

Figure 3.3: Roughness derived from the $1 \mathrm{~m}$ resolution LiDAR digital elevation model . 23

Figure 3.4: Composite band image from combining slope, profile curvature, and roughness data. 25

Figure 3.5: NDVI derived from the $2.5 \mathrm{~m}$ resolution color infrared imagery 26

Figure 3.6: Workflow of Object-Oriented Image Analysis (OOIA) and classification in ArcGIS 10.5

Figure 3.7: Segmented image generated from 1m resolution LiDAR ....................... 29

Figure 3.8: Segmented image generated from $2.5 \mathrm{~m}$ resolution LiDAR ..................... 30

Figure 3.9: Segmented image generated from $5 \mathrm{~m}$ resolution LiDAR ....................... 31

Figure 3.10: Training sample locations in the study area ...................................... 33

Figure 4.1: Classified Image from 1m resolution LiDAR with NDVI .......................... 40

Figure 4.2: Classified Image from 2.5m resolution LiDAR with NDVI ....................... 41

Figure 4.3: Classified Image from 5m resolution LiDAR with NDVI .......................... 42

Figure 4.4: Classified Image from $1 \mathrm{~m}$ resolution LiDAR without NDVI....................... 43

Figure 4.5: Classified Image from 2.5m resolution LiDAR without NDVI .................... 44 
Figure 4.6: Classified image from $5 \mathrm{~m}$ resolution LiDAR without NDVI

Figure 4.7: Combined classification map from $1 \mathrm{~m}, 2.5 \mathrm{~m}$, and $5 \mathrm{~m}$ resolution classified images with NDVI

Figure 4.8: Combined classified image from $1 \mathrm{~m}, 2.5 \mathrm{~m}$, and $5 \mathrm{~m}$ resolution LiDAR data with NDVI

Figure 4.9: Combined map from $1 \mathrm{~m}, 2.5 \mathrm{~m}$, and $5 \mathrm{~m}$ resolution classified images without

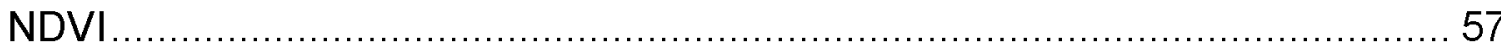

Figure 4.10: Combined classified image from $1 \mathrm{~m}, 2.5 \mathrm{~m}$, and $5 \mathrm{~m}$ resolution LiDAR data without NDVI. 60 


\section{List of Tables}

Page

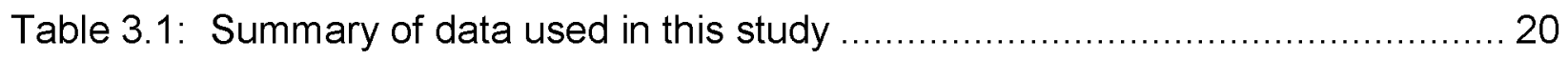

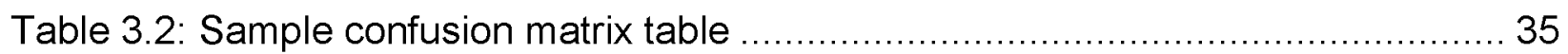

Table 4.1: Confusion matrix table for $1 \mathrm{~m}$ resolution LiDAR with NDVI ..................... 46

Table 4.2: Confusion matrix table for $1 \mathrm{~m}$ resolution LiDAR without NDVI ................... 46

Table 4.3: Confusion matrix table for $2.5 \mathrm{~m}$ resolution LiDAR with NDVI ................... 47

Table 4.4: Confusion matrix table for $2.5 \mathrm{~m}$ resolution LiDAR without NDVI ................ 47

Table 4.5: Confusion matrix table for $5 \mathrm{~m}$ resolution LiDAR with NDVI ..................... 48

Table 4.6: Confusion matrix table for $5 \mathrm{~m}$ resolution LiDAR without NDVI .................. 48

Table 4.7: Summary of overall accuracy and kappa statistics for multi-resolution LiDAR data

Table 4.8: Summary of producer accuracy and user accuracy in landslide locations for multi-resolution LiDAR data 50

Table 4.9: Summary of producer accuracy and user accuracy in landslide susceptible locations for multi-resolution LiDAR data..

Table 4.10: Summary of producer accuracy and user accuracy in stable locations for multi-resolution LiDAR data

Table 4.11: Reclassified values of the combined image from Fig. 4.7

Table 4.12: Confusion matrix table for combined classified image from $1 \mathrm{~m}, 2.5 \mathrm{~m}$, and $5 \mathrm{~m}$ resolution LiDAR with NDVI. 56

Table 4.13: Reclassified values of the combined image from Fig. 4.9 59 
Table 4.14: Confusion matrix table for combined classified image from $1 \mathrm{~m}, 2.5 \mathrm{~m}$, and $5 \mathrm{~m}$ resolution LiDAR without NDVI 61 


\section{Acknowledgements}

First and foremost, I would like to thank my advisor, Dr. Margaret Darrow, for her continuous support, guidance, and encouragement during my two years of study at the University of Alaska Fairbanks (UAF). She has given me the moral support that I needed to complete this thesis. I immensely enjoyed every meeting and field trips with her. I could not have asked for a better advisor. Thank you, Dr. Darrow, for being there for me.

My thesis committee has been amazing in guiding me during this whole process. Thank you, Dr. Paul Metz, Dr. Mike Hendricks, and Dr. Ronald Daanen, for being my advisors.

I would especially like to thank Dr. Hendricks for all the GIS master classes that he taught me. He has given me immense support and time in learning GIS and helped me going through the technical challenges of this thesis. He always came up with new ideas and I thoroughly enjoyed our every discussion.

Thanks to the Alaska Division of Geological \& Geophysical Surveys for their funding to support this research. I would like to thank De Anne Stevens and Dr. Trent Hubbard for their support during my internship at Alaska Division of Geological and Geophysical Surveys (DGGS).

Lastly, I would like to thank my wife, Somaiya, for her unconditional support and encouragement to finish this thesis. 


\section{Chapter 1 Introduction}

A landslide is defined as the movement of a mass of rock, earth, or debris down a slope (Cruden, 1991). A more inclusive term for a landslide is slope movement, as landslides are not limited to sliding and involve other processes like debris flows as well. Slope movements can be classified into five groups: falls, topples, spreads, slides, and flows (Varnes, 1978). When two or more of these slope movements occur, this is considered as complex. Landslides can occur independently or in association with other natural hazards such as earthquakes, flooding, etc. Since landslides can occur on a massive scale, they represent a serious threat to human life and the built environment. For example, on June 12, 2017, 156 people died in Bangladesh from a rain-induced landslide (Paul and Hussain, 2017). In 2016, the 7.8 magnitude Kaikōura earthquake triggered more than 10,000 landslides in New Zealand (Massey et al., 2018). On May 2, 2014, around 2,000 people were killed because of the Ab Barak landslide in Afghanistan (Witze, 2014). The Oso Landslide on March 22, 2014 killed 43 people in Washington State, USA (Wartman et al., 2016). As population increases, more people are killed by landslides because of a general lack of knowledge about landslide occurrence and hazard preparation. Identifying historic landslide locations and potential landslide zones can help both the general public and stakeholder agencies to manage this geohazard better.

Landslides can initiate within bedrock or within the soil mass that covers bedrock. They drastically change the morphology of a landscape (Kavzoglu et al., 2014; Lee et al., 2012; Pradhan and Lee, 2009), changing the slope, aspect, and curvature of the ground surface. These changes provide identifying characteristics to geomorphologists 
and, together with meteorological factors, help to identify potential landslide zones (Guzzetti et al., 1999; Kavzoglu et al., 2014).

\subsection{Landslide Studies}

A significant number of studies have been made using various techniques to identify landslides and to develop landslide susceptibility maps. Researchers around the world have used Geographic Information System (GIS) tools to identify and to map landslides; Guzzetti et al. (1999) provided a review of these GIS techniques. The one common philosophy in developing susceptibility maps is that future landslides will occur under similar conditions as the past and present landslides. Hence, a landslide inventory is an important first step in landslide susceptibility mapping (Guzzetti et al., 1999). Light Detection and Ranging (LiDAR), Interferometric Synthetic Aperture Radar (IfSAR), and satellite imageries (e.g., WorldView-2, Spot-5) have made it possible to identify landslides from before- and after-images of an area; however, the scale or resolution of these data plays an important factor in identifying landslides, as smallscale landslides are often not visible in coarser resolution images. In this study, I made a landslide inventory from visual inspection of hillshade images from $1 \mathrm{~m}$ resolution LiDAR data, which is considered fine resolution data. I took a multiscale approach by resampling the $1 \mathrm{~m}$ LiDAR data to $2.5 \mathrm{~m}$ and $5 \mathrm{~m}$ scales. I then used the inventory in subsequent analyses.

\subsection{Qualitative Analysis}

The models used by different researchers to identify landslides can be divided into two broad categories: qualitative and quantitative. Almost all the methods use GIS 
in conjunction with other software (e.g., Matlab, R) to do the analysis. The qualitative approach relies on visual identification of landslides from satellite and/or aerial imagery, field surveying, and interpretation of historical photographs. These techniques are timeconsuming and subjective, and the accuracy depends on the expertise of the person involved. High-resolution imagery with sufficient geometric and radiometric corrections is needed to identify landslides visually (Dahal, 2014; Fiorucci et al., 2011), and often current digital imagery is not available. In this study, fine resolution $1 \mathrm{~m}$ LiDAR data have made it possible to create a landslide inventory from visual inspection.

\subsection{Quantitative Analysis}

Quantitative analysis can be divided into three categories: 1) probabilistic models, 2) statistical models, and 3) machine learning algorithms. Different quantitative models are described in the subsequent sections.

\subsubsection{Frequency Ratio Analysis}

Frequency Ratio Analysis (FRA) is one popular probability model used in making susceptibility maps (Chen et al., 2016; Choi et al., 2012; Kumar and Anbalagan, 2015; Lee et al., 2012; Lee and Pradhan, 2007; Nourani et al., 2014; Ramesh and Anbazhagan, 2015; Son et al., 2016; Yilmaz, 2009; Youssef et al., 2015; Zhang et al., 2016b). FRA depends on observed relationships between landslide occurrence and landslide causative factors, such as land cover, lithology, elevation, slope, aspect, curvature, rainfall, and distance from lineaments. As past landslide events are needed to identify the relationship between landslide occurrence and causative factors, this method requires a detailed inventory of past landslide locations. The FRA method uses 
a ratio of areas where landslides have occurred to the total area (Pradhan and Lee, 2009). If the ratio is greater than 1 then the relationship between the landslide and factor's range or type is strong. If the ratio is less than 1 then the relationship between landslide and factor's range or type is weak (Lee and Sambath, 2006). All frequency ratio values are summed to calculate the susceptibility index in a training area. Higher susceptibility index values represent a higher landslide hazard.

\subsubsection{Logistic Regression}

Statistical methods are frequently used in landslide studies. While both bivariate and multivariate statistical analyses have been employed, Logistic Regression (LR) is a multivariate statistical technique that has been used often by researchers (Budimir et al., 2015; Choi et al., 2012; Devkota et al., 2013; Dieu Tien et al., 2011; Falaschi et al., 2009; Felicisimo et al., 2013; Kavzoglu et al., 2014; Lee et al., 2012; Lee and Pradhan,

2007; Lee and Sambath, 2006; Nourani et al., 2014; Pourghasemi et al., 2014; Regmi et al., 2014; Xu et al., 2013; Yilmaz, 2009; Zhang et al., 2016a). LR provides a quantification of the relationship between landslide occurrence and landslide causative factors (Falaschi et al., 2009). In this method, there is one dependent variable and multiple independent variables (landslide causative factors). One advantage of LR is that variables do not necessarily have to be normally distributed. The dependent variable is binary, being either 0 (absence of a landslide) or 1 (presence of a landslide). A linear regression equation is formed among the independent variables. The probability of a landslide in an area is calculated using:

$$
p=\frac{1}{1-e^{-z}}
$$


where $p$ is the probability of an event occurring and $z$ is the linear combination among the independent variables (Lee and Pradhan, 2007). The parameter $z$ is calculated as:

$$
z=b_{0}+b_{1} x_{1}+b_{2} x_{2}+b_{3} x_{3}+b_{n} x_{n}
$$

where $b_{0}$ is the intercept, $b_{1}$ through $b_{n}$ are coefficients, and $x_{1}$ through $x_{n}$ are the independent variables. The probability of a landslide occurrence is calculated using Equations (1) and (2). A spatial database is created by converting the raster files (slope, aspect, curvature, etc.) into American Standard Code for Information Interchange (ASCII) format. Then they are analyzed using a statistical software package (e.g., R), and the correlation between a landslide event and each factor is calculated. Converting large amounts of data into ASCII format and then returning them back to rasters to use in GIS is a cumbersome and time-consuming process (Lee and Pradhan, 2007; Nourani et al., 2014). Also, to give satisfactory results, there has to be a linear relationship among the variables. It is often the case in landslide studies that data are nonlinear, and if the model over-fits the data, then it will contain noise resulting in many false positives.

\subsubsection{Weights of Evidence}

One bivariate model that is often used in landslide susceptibility mapping is the weights of evidence model (WoE) (Ahmed and Dewan, 2017; Chen et al., 2016; Lee et al., 2012; Mohammady et al., 2012; Neuhäuser and Terhorst, 2007; Ozdemir and Altural, 2013; Regmi et al., 2010; Van Westen et al., 2003). A landslide inventory is required to find the weights of the landslide causative factors. This method calculates the weight for each landslide predictive factor based on the presence or absence of landslides within an area. Positive and negative weights are assigned to different classes of a thematic map (e.g., slope, curvature, lithology, etc.). One drawback to this 
assessment is that when probability reaches 1 for the hypothesis (in this case, landslide occurrences), it does not leave any room for error regarding other class types or unexpected situations (Ahmed and Dewan, 2017).

\subsubsection{Artificial Neural Networks and Support Vector Machines}

Landslide mapping can be viewed as a classification problem where the main goal is to classify either landslide-prone areas or non-landslide areas (Ballabio and Sterlacchini, 2012). Machine learning algorithms, such as Artificial Neural Networks (ANN) and Support Vector Machines (SVM), are used to classify landslide-prone areas and can classify large amount of data. With advancements in processor computing power, machine learning techniques are becoming more and more feasible.

Several researchers have used SVM to make landslide susceptibility maps (Ballabio and Sterlacchini, 2012; Hong et al., 2016; Kavzoglu et al., 2014; Marjanović et al., 2011; Micheletti et al., 2014; Pradhan, 2013; Su et al., 2015; Wu et al., 2014; Xu et al., 2012; Xu et al., 2016; Yao et al., 2008). SVM provides better results than other classification tools in identifying landslide-prone areas. It creates a high dimensional feature space through nonlinear mapping. The input vectors are mapped in this space and an optimal separating hyperplane is constructed (Vapnik, 1995). The method can classify $n$ number of observations by separating them using the hyperplane, which is defined by a function. SVM can classify samples even if they overlap each other. Linear methods like logistic regression do not perform well when only DEM-derived parameters are available; however, SVM works well in this scenario and preserves most of its performance capability (Ballabio and Sterlacchini, 2012). SVM, like other machine 
learning algorithms, require a large amount of training samples to be able to perform satisfactorily. In this study, I used SVM for training samples from the landslide inventory.

ANN is a machine learning technique that is often used with the landslide susceptibility problem (Bi et al., 2014; Choi et al., 2012; Dou et al., 2015; Falaschi et al., 2009; Gelisli et al., 2015; Lee et al., 2012; Lee et al., 2004; Li et al., 2012; Moosavi et al., 2014; Nourani et al., 2014; Pradhan and Lee, 2009; Samodra et al., 2017; Tsangaratos and Benardos, 2014; Xu et al., 2016; Yilmaz, 2009). It can classify nonlinear data. A neural network is developed by imitating the human brain structure. The ANN model is trained using a set of associated input and output values as examples. Most landslide susceptibility problems addressed using ANN have used a back-propagation algorithm to train the network. In ANN there is an input layer, one or more hidden layers, one output layer, weights, biases, and an activation function. Landslide causative factors are fed into the input layer after a data normalization process. The back-propagation algorithm then analyzes the input to find the appropriate weight and biases for the network. The output values represent landslide occurrence or absence. Several mathematical packages (e.g., MATLAB) are available to use the ANN, and it can be trained satisfactorily provided there is an adequate amount of training data. The training is continued until a minimal error is achieved. After the training, ANN is used as a feed forward network to produce a classification on test samples (Pradhan and Lee, 2009). It often takes significant time to train the network and there are no set rules in selecting the initial weight and biases.

FRA, LR, and WoE are more conventional techniques than ANN and SVM. ANN and SVM are pixel-based approaches where each pixel is considered in the analysis for 
landslide occurrence or absence. Moosavi et al. (2014) demonstrated that no significant differences existed between the ANN and SVM approaches.

\subsubsection{Image Classification Approach}

Image classification techniques, also pixel-based approaches, have been implemented in landslide identification. Maximum likelihood classification, parallelepiped, ISODATA, and K-mean are some examples of pixel-based image classification tools. Supervised image classification methods can be applied using tools in GIS (Kasai et al., 2009). Guzzetti et al. (2012) point out that one problem with pixelbased approaches is that they do not consider the local geomorphological context (e.g., size, shape, position) of the extracted feature. Pixel-based approaches can identify head scarps or sets of escarpments but not the whole body of the landslide, and it is difficult to map landslides in a large area with the aid of only a single feature such as the head scarps.

\subsubsection{Object Oriented Image Analysis}

The problems of pixel-based approaches can be overcome using the more advanced technique of Object Oriented Image Analysis (OOIA), which has been used successfully by Aksoy and Ercanoglu (2012), Li et al. (2015), and Martha et al. (2010), to identify landslides. The availability of high-resolution LiDAR digital elevation models (DEMs) has made OOIA possible. This approach is a semi-automatic method of identifying landforms and other objects by extracting features using spectral, spatial, and morphometric attributes of segmented images. It has been used widely in natural resource management, urban planning, landform studies, agriculture and forestry, and Aksoy and Ercanoglu (2012), Blaschke (2010), Drăguţ and Blaschke (2006), and 
Martha et al. (2010) have used OOIA in landslide studies. Considerable progress has been made using OOIA as a tool in spatial planning (Blaschke, 2010). Specialized software is available that can handle OOIA well. Recently, the ArcGIS software was equipped with OOIA, and its capability in landslide identification is worth investigating.

In OOIA, landslides are considered objects with certain characteristics or signature values. Instead of considering each pixel for landslide presence or absence, landslides are considered as objects with certain characteristic signatures. Neighboring pixels are considered to have the same characteristics. There are two steps in OOIA: 1) image segmentation and 2) image classification. A segmentation process is applied on the image to clear out noise and for smoothing. Training samples are taken as objects. All objects with similar characteristics are given the same attribute or put into the same group. After training the model, it is applied to a different location to extract the same features, or to classify the image. As there is human involvement in this process, this method is considered semi-automatic.

Some researchers have used very different approaches in landslide identification. For example, Leshchinsky et al. (2015) developed the Contour Connection Method (CCM). It is neither statistical nor pixel-based. This method is a new algorithm to identify landslides using a python script in GIS. A LiDAR-derived DEM is used to make contours, and each contour has nodal connection with other contours based on a set of values. Leshchinsky et al. (2015) demonstrated that the density of nodal connections is representative of different parts (e.g., head scarp, body, and fan deposit) of a landslide. 


\subsection{Goal of This Research and Thesis Organization}

The goal of this research is to develop a methodology that can be used in Interior Alaska to identify landslides and potential landslide zones. The study area consists of $39.76 \mathrm{~km}^{2}$ of rugged terrain without much road access; hence, it is difficult to map landslides using traditional field mapping techniques. At the current time, no detailed landslide inventory exists for Interior Alaska. The inventory prepared for the study area only provides locations of landslides and landslide susceptible areas, but does not provide any other information necessary to use the above-mentioned techniques (e.g., distance to faults and lineaments, rainfall density, etc.). Hence, traditional techniques are not suitable for use in this study.

Given this data limitation, I developed a modified image classification approach to identify landslide locations from available data, which were LiDAR derivatives (e.g., slope, curvature, and roughness) and the normalized difference vegetation index (NDVI) obtained from color infrared imagery. Van Den Eeckhaut et al. (2012) used LiDAR derivatives to identify landslides in Belgium using eCognition software. In contrast, I used LiDAR derivatives in ArcGIS 10.5 and a supervised image classification approach with segmented images prepared from OOIA classification techniques. The samples were trained using an SVM classifier, which is a machine learning algorithm to identify landslide and landslide susceptible locations. The developed methodology was implemented at different resolutions (i.e., $2.5 \mathrm{~m}, 5 \mathrm{~m}$ ) of LiDAR data. Finally, I used accuracy assessment techniques to quantify the results.

This thesis is divided into six chapters. Chapter 1 is a review of previous studies on landslide identification and discusses various techniques associated with landslide 
identification. Chapter 2 provides descriptions of the training and test sites. Chapter 3 describes the methodology used in this research, including a description of the accuracy assessment technique. In Chapter 4 , I discuss the results derived from the accuracy assessment of LiDAR images at $1 \mathrm{~m}, 2.5 \mathrm{~m}$, and $5 \mathrm{~m}$ scales, and Chapter 5 concludes with a summary of this research, its limitations, and suggestions for future studies. 


\section{Chapter 2 Study Area}

The study area broadly consists of road corridors within Interior Alaska (Fig. 2.1). I prepared a landslide inventory from four study sites (i.e., Slate Creek, Copper River, Richardson, and Yukon). I chose multiple training sites in different geological settings to improve landslide identification within the long transportation corridors of Interior Alaska (Fig. 2.2).

\subsection{Slate Creek}

The Slate Creek landslide (Fig. 2.2a) is located on an east-facing river terrace near Mile Post (MP) 258 along the Parks Highway and adjacent to the Nenana River, approximately nine miles north of Healy, Alaska. It is located in the northern foothills of the Alaska Range, in which permafrost is present (Wahrhaftig, 1965). The landslide occurred in the Tertiary Nenana Gravel Unit, which is a poorly-consolidated fluvial deposit consisting mostly of pebble to boulder conglomerate and coarse-grained sandstone, with interbedded mudflow deposits, thin claystone layers, and local thin lignite beds (Wahrhaftig, 1970). As four distinct glacial advances have been recognized in the Nenana River area, the landslide area also contains outwash gravel, which overlays the Nenana Gravel on the top of the river terrace (Wahrhaftig and Black, 1958).

\subsection{Copper River}

The Copper River training site (Fig. 2.2b) is located to the west of Richardson Highway near MP112 along the Tazlina River, which is a tributary of the Copper River. 


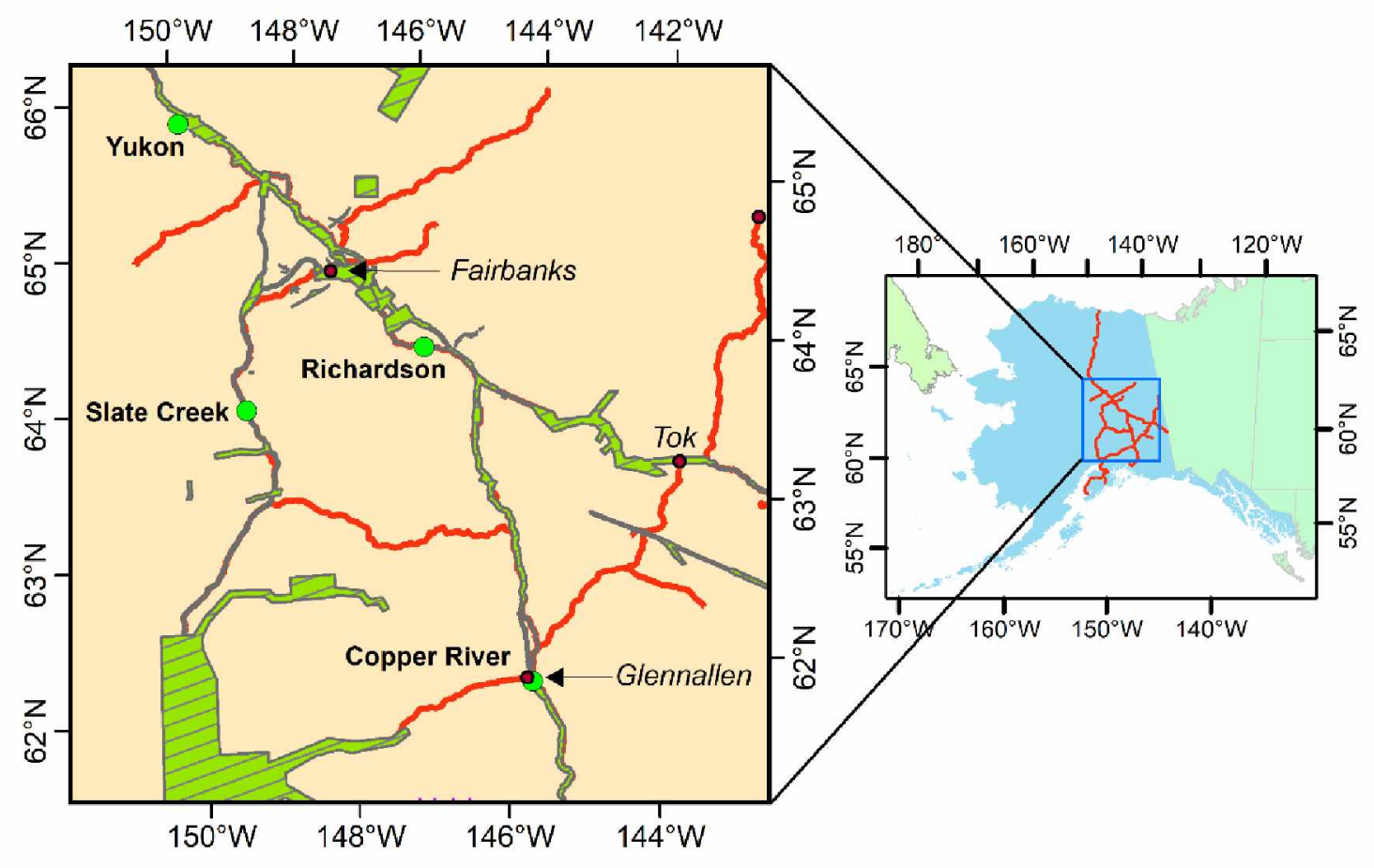

Figure 2.1: Location of study sites: Slate Creek, Copper River, Richardson, and Yukon. Highways are indicated by red lines, and in the inset, areas with LiDAR coverage are indicated by a green hatched pattern. Nearby communities are indicated in italicized text. 


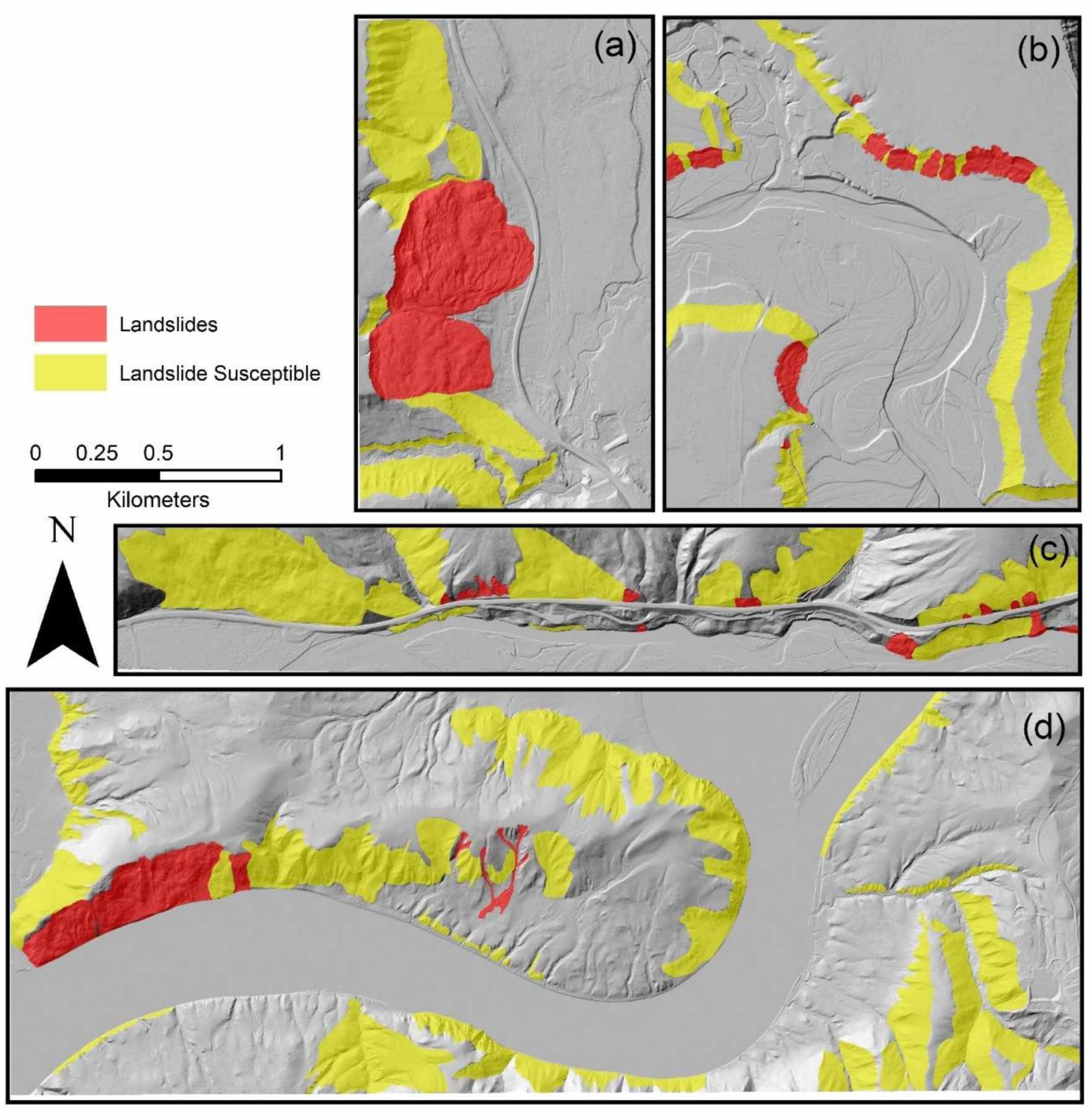

Figure 2.2: Landslide inventory prepared using visual inspection of LiDAR data:

(a) Slate Creek, (b) Copper River, (c) Richardson, and (d) Yukon. The base layer is a hillshade image derived from $1 \mathrm{~m}$ resolution LiDAR (Hubbard et al., 2011). 
This training site is in the Copper River Lowland physiographic province (Wahrhaftig, 1965) and consists of a relatively smooth plain that is entrenched by the Copper River and its tributaries. The mountains of the Alaska, Talkeetna, Chugach, and Wrangell Ranges surround the Copper River Basin. During the Pleistocene glaciations, glaciers advanced from these mountains and dammed the basin's drainage, forming a proglacial lake known as Lake Atna (Ferrians et al., 1983). Thus, the soils of the Copper River Basin mainly consist of glaciolacustrine sediments. Permafrost began to form in these sediments following the retreat of glaciers and drainage of the lake (Ferrians et al., 1983; Wahrhaftig, 1965; Wiedmer et al., 2010).

\subsection{Richardson Highway MP296}

This site is located along the Richardson Highway, starting at MP296 and extending to the north to MP299 (Fig. 2.2c). It is in the Yukon-Tanana Upland physiographic province, which is characterized by rounded even-topped ridges with gentle side slopes (Wahrhaftig, 1965). The landslides on the north side of the highway are in pelitic schist and quartzite of Devonian or older age (Wilson et al., 2015). To the south of the highway, the slopes are covered with unconsolidated surficial deposits of Quaternary age (Wilson et al., 2015). The study site runs parallel to the Tanana River, and south-facing slopes in the low terraces of the Tanana River may contain widespread, shallow, and locally ice-rich permafrost (Reger et al., 2008; Reger and Solie, 2008). 


\subsection{Yukon River}

The training site along the Yukon River is located west of the E.L. Patton Bridge (Fig. 2.2d). This area is on the boundary between the Kokrine-Hodzana Highlands, the Rampart Trough, and the Yukon-Tanana Upland physiographic provinces (Koehler et al., 2013; Wahrhaftig, 1965). Bedrock outcrops exposed along the river mainly consist of Mississippian-Triassic intrusive and extrusive mafic igneous rocks, with some sedimentary rocks such as argillite, chert, greywacke, shale, and limestone (Wilson et al., 2015). Frozen surficial deposits mainly consist of loess, which is 1.5 - to 15 -m thick on ridge crests, and ice-rich in stream valleys (Koehler, 2011; Koehler et al., 2013; Weber et al., 1992; Wilson et al., 2015). 


\section{Chapter 3 Methodology}

\subsection{Data Sets}

A publicly available Light Detection and Ranging (LiDAR) data set was used in this research. The Alaska Division of Geological \& Geophysical Surveys (DGGS) hosts $1 \mathrm{~m}$ resolution LiDAR data for an area of $7,770 \mathrm{~km}^{2}\left(3,000 \mathrm{mi}^{2}\right)$ with $1.6-\mathrm{km}(1-\mathrm{mi})$ width coverage along major infrastructure corridors (Hubbard et al., 2011). The more detailed LiDAR data are useful for characterization of geomorphic features, active faults, and other surficial geologic landforms. I resampled the LiDAR DEMs to $2.5 \mathrm{~m}$ and $5 \mathrm{~m}$ scales using the bilinear interpolation method, which calculates the value of each pixel by averaging the values of the four surrounding pixels.

To calculate the normalized difference vegetation index (NDVI), I used Spot 5 color infrared imagery. This imagery is available for the entire state from the Alaska Statewide Digital Mapping Initiative (SDMI). This data set was acquired from the Division of Forestry, Department of Natural Resources website. Table 3.1 summarizes the details of the data used in this study.

\subsection{LiDAR Derivatives}

Slope, profile curvature, and roughness describe the morphometric properties of a landslide and generate a unique signature for different landforms; Fig. 3.1 to Fig. 3.3 provide examples of these characteristics. Slope describes the degree of flatness (Fig. 3.1); one fundamental characteristic of a landslide is a break in slope. Profile curvature is the curvature of the surface in the direction of slope, and for rotational landslides a change in curvature from body to toe is distinguishable (Fig. 3.2). Roughness is perhaps 
Table 3.1: Summary of data used in this study

\begin{tabular}{lcccc}
\hline Data Type & Sensor & Spatial Reference & Scale & Data Derivatives \\
\hline LiDAR DEM & Airborne & NAD 1983 UTM & $\begin{array}{c}1 \mathrm{~m} \times 1 \mathrm{~m} \\
2.5 \mathrm{~m} \times 2.5 \mathrm{~m} \\
5 \mathrm{~m} \times 5 \mathrm{~m}\end{array}$ & $\begin{array}{c}\text { Plope } \\
\text { Profile Curvature } \\
\text { Roughness }\end{array}$ \\
\hline $\begin{array}{l}\text { Color } \\
\text { Infrared } \\
\text { Image }\end{array}$ & Spot-5 & NAD 1983 UTM & $2.5 \mathrm{~m} \times 2.5 \mathrm{~m}$ & $\begin{array}{c}\text { Normalized } \\
\text { Difference } \\
\text { Vegetation Index } \\
\text { (NDVI) }\end{array}$ \\
\hline
\end{tabular}




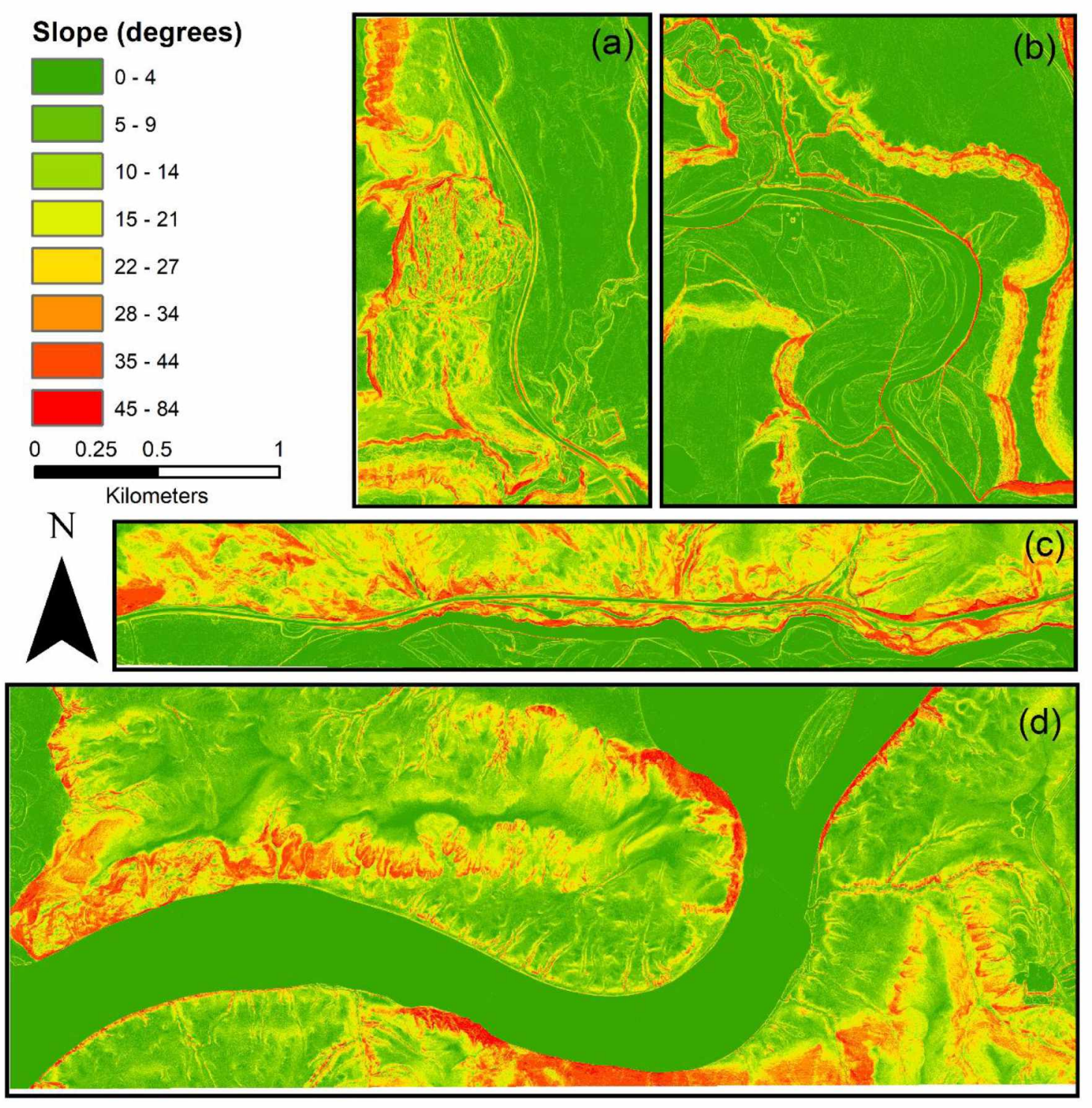

Figure 3.1: Slope derived from the $1 \mathrm{~m}$ resolution LiDAR digital elevation model. Study sites are (a) Slate Creek, (b) Copper River, (c) Richardson, and (d) Yukon. 


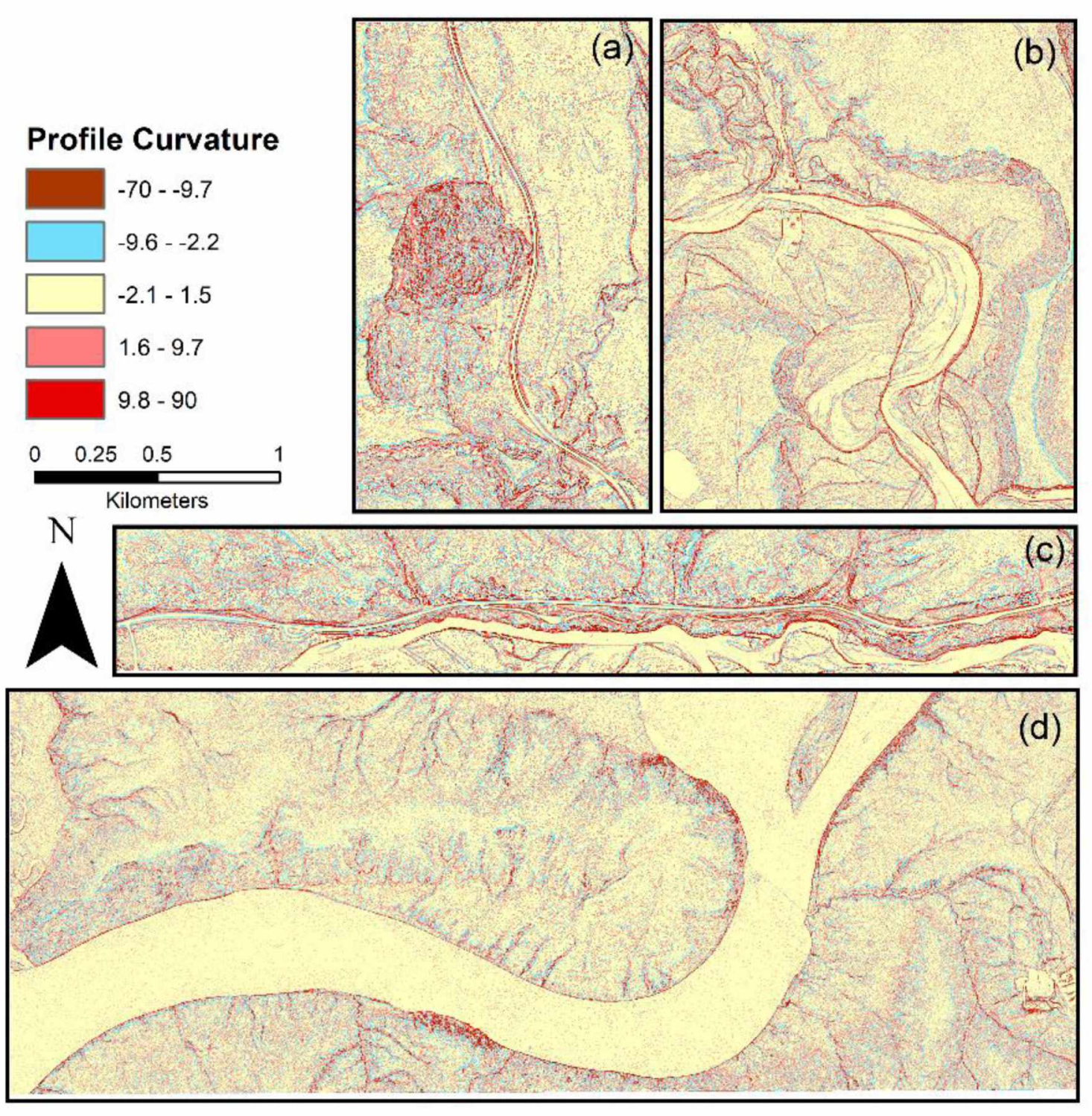

Figure 3.2: Profile curvature derived from the $1 \mathrm{~m}$ resolution LiDAR digital elevation model. Study sites are (a) Slate Creek, (b) Copper River, (c) Richardson, and (d) Yukon. 

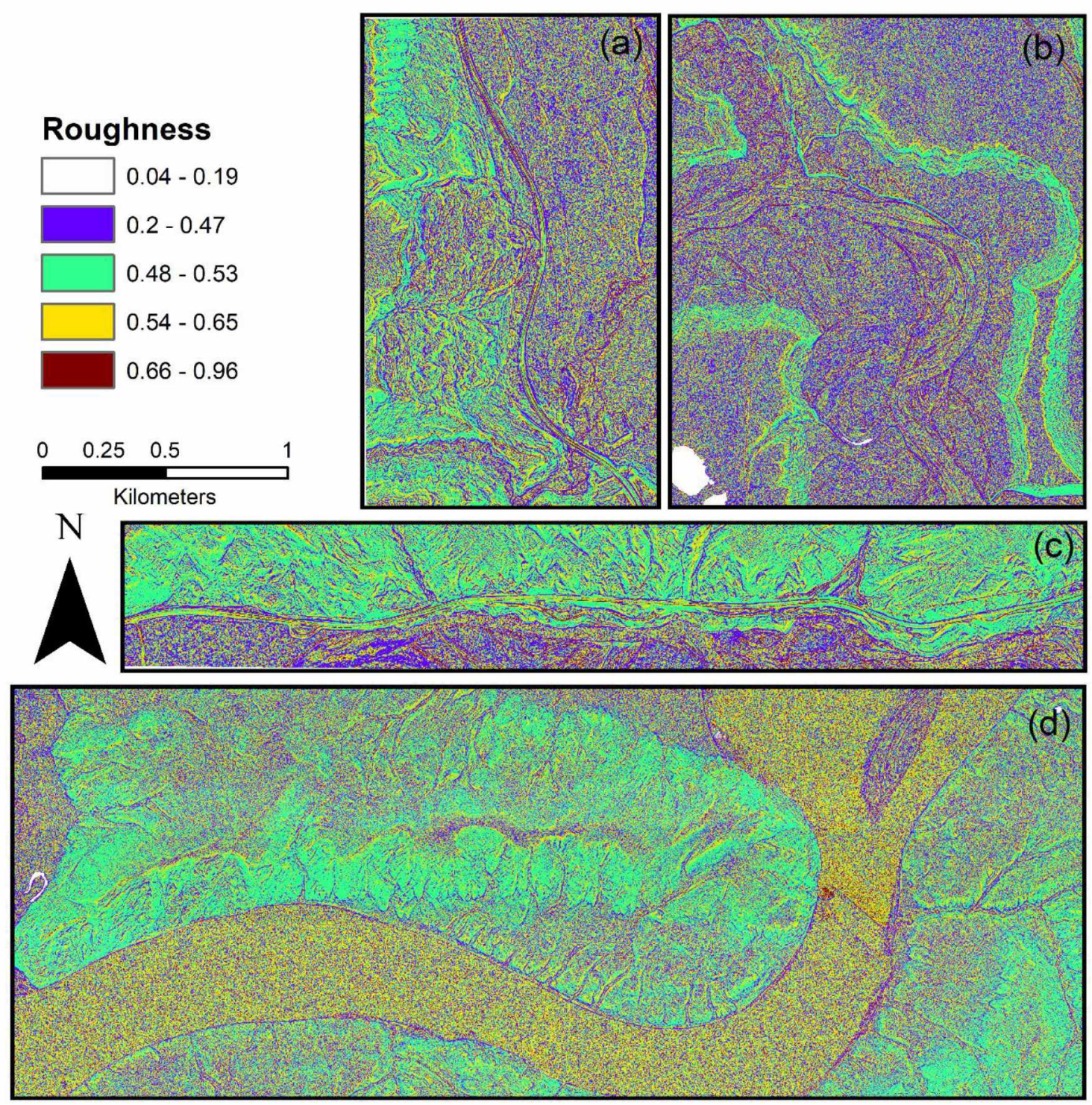

Figure 3.3: Roughness derived from the $1 \mathrm{~m}$ resolution LiDAR digital elevation model. Study sites are (a) Slate Creek, (b) Copper River, (c) Richardson, and (d) Yukon. 
the most important characteristic of a landslide. Surface roughness describes the variability of a topographic surface at a certain scale (Grohmann et al., 2011). Common surface roughness measures are standard deviation of residual topography, standard deviation of profile curvature, standard deviation of slope, etc. Some methods can show local relief while other methods are good for delineating regional relief. The choice of measurement depends on the scale of the landform of interest. A landslide body has a higher roughness index than its surroundings. While roughness can be calculated using multiple techniques (Grohmann et al., 2011), I used the topographic roughness index (Fig. 3.3) (Jenness, 2004). I used Equation (3) to calculate roughness using a focal statistics tool with a $5 \times 5$ cell moving window from a LiDAR digital elevation model (DEM):

$$
\text { roughness }=\frac{\text { mean-minimum }}{\text { maximum-minimum }}
$$

where mean, minimum, and maximum are the names of rasters derived from the DEM.

The three thematic rasters (i.e., slope, profile curvature, and roughness) derived from LiDAR data were combined to create a multispectral composite band image (Fig. 3.4), where Bands 1, 2, and 3 were slope, profile curvature, and roughness rasters, respectively. The composite band image was used to generate a segmented image. I also used NDVI in the subsequent training phase (Fig. 3.5). NDVI is an index parameter that indicates the health of different plants. Since landslide head scarps often do not support vegetation, I hypothesized that the NDVI may work as an identifying parameter. Fig. 3.6 illustrates the workflow for the OOIA. 


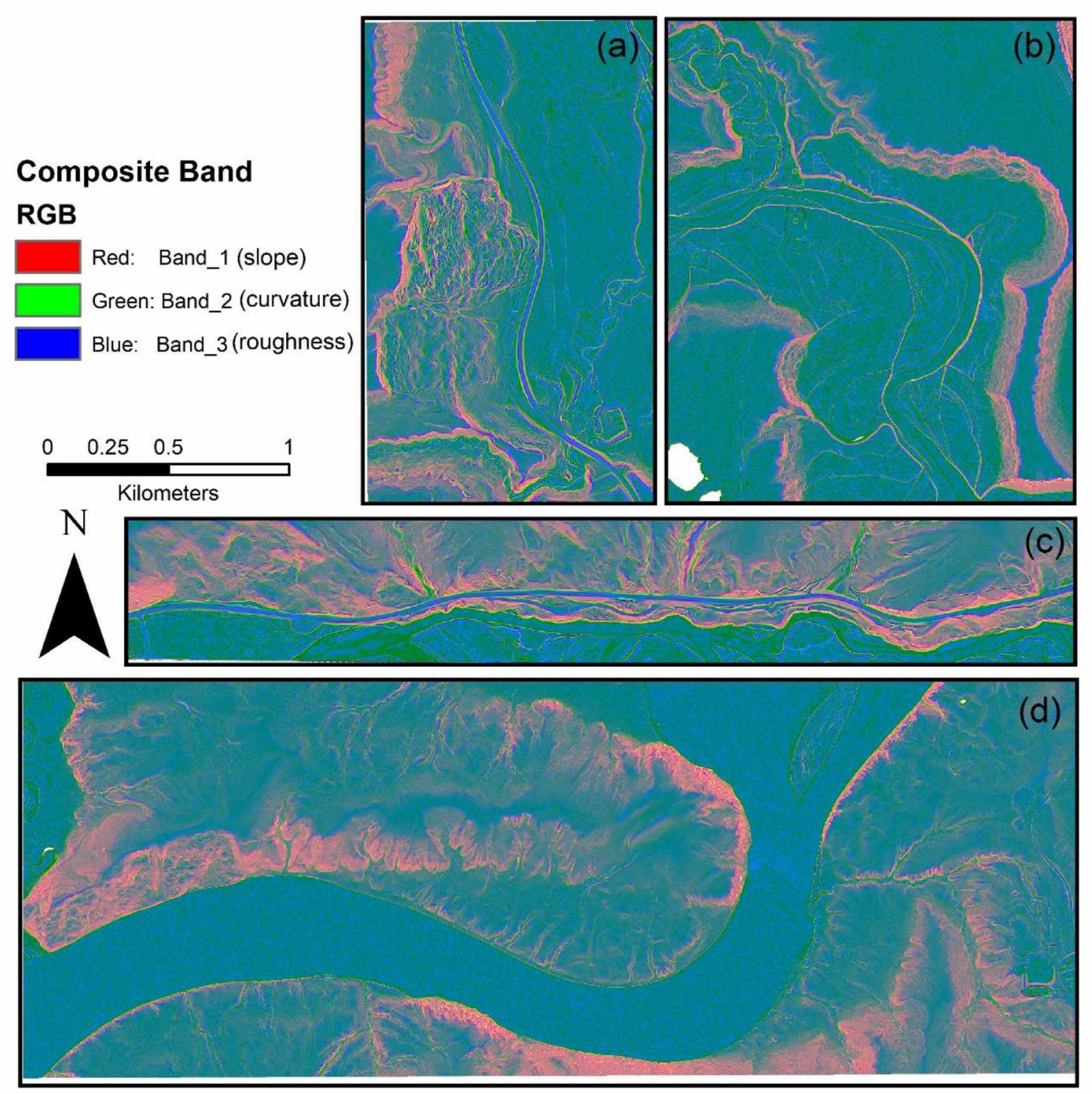

Figure 3.4: Composite band image from combining slope, profile curvature, and roughness data. Study sites are (a) Slate Creek, (b) Copper River, (c) Richardson, and (d) Yukon. 


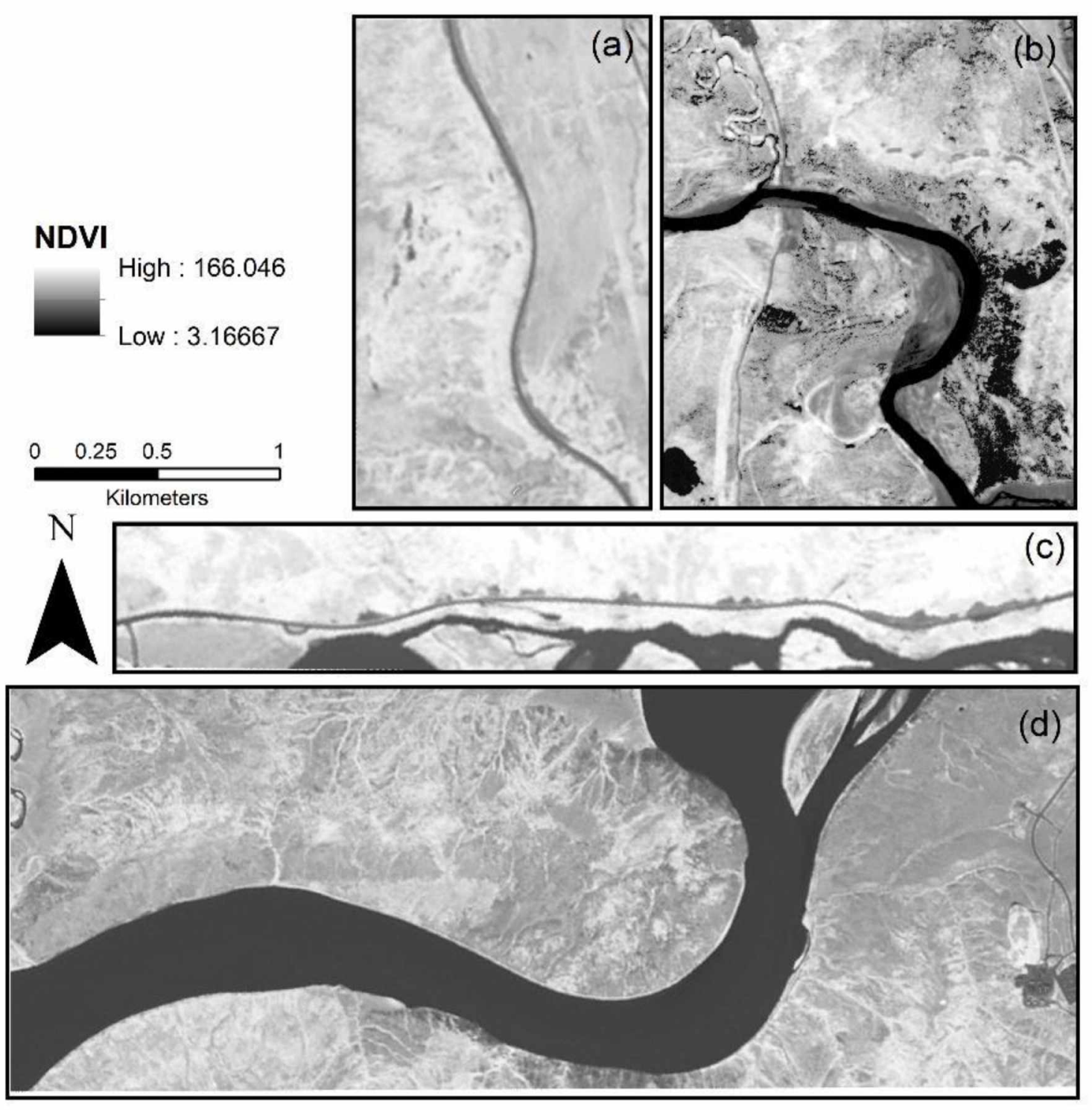

Figure 3.5: NDVI derived from the $2.5 \mathrm{~m}$ resolution color infrared imagery. Study sites are (a) Slate Creek, (b) Copper River, (c) Richardson, and (d) Yukon. 


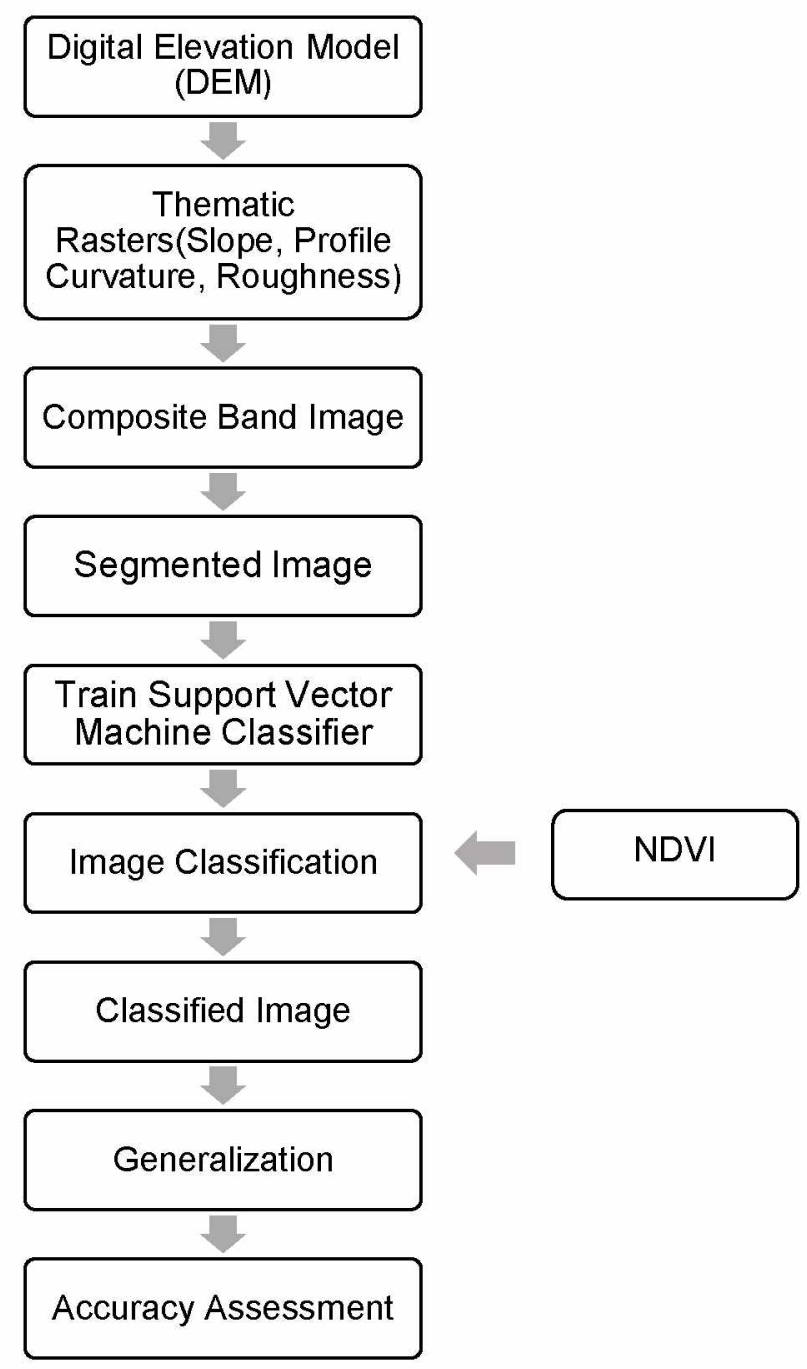

Figure 3.6: Workflow of Object-Oriented Image Analysis (OOIA) and classification in ArcGIS 10.5 . 


\subsection{Image Segmentation}

A segmented image is generated using the "segment mean shift" tool in ArcGIS 10.5. Accuracy of the classification depends on the segmentation process. In this process, an image is segmented based on its spectral, spatial, and morphometric properties.

Prior to segmentation, I determined values for spectral detail, spatial detail, and minimum segment size. Appropriate values for these parameters are often found by trial and error (Aksoy and Ercanoglu, 2012; Drăguţ and Blaschke, 2006). When the spectral detail is increased there is more variation throughout the segmented raster. When spatial detail is increased, there is more than one unique object in the segmented raster. Increasing the minimum segment size lessens the detail (ESRI, 2017). For this analysis, I used a spectral detail of 18 , a spatial detail of 10 , and a minimum segment size of 300 pixels.

I generated three segmented images for $1 \mathrm{~m}, 2.5 \mathrm{~m}$, and $5 \mathrm{~m}$ resolution LiDAR data (Fig. 3.7, Fig. 3.8, and Fig. 3.9, respectively). Segmentation divided the composited band image into different segments. For the $1 \mathrm{~m} \times 1 \mathrm{~m}$ segmented data, the minimum and maximum segments had areas of $6.4 \times 10^{-7} \mathrm{~km}^{2}$ and $2.95 \mathrm{~km}^{2}$, respectively. For the $2.5 \mathrm{~m} \times 2.5 \mathrm{~m}$ data, the minimum and maximum segments were $4.0 \times 10^{-6} \mathrm{~km}^{2}$ and $4.18 \mathrm{~km}^{2}$, respectively, and for the $5 \mathrm{~m} \times 5 \mathrm{~m}$ data, the minimum and maximum segments were $1.6 \times 10^{-5} \mathrm{~km}^{2} 5.62 \mathrm{~km}^{2}$, respectively. 


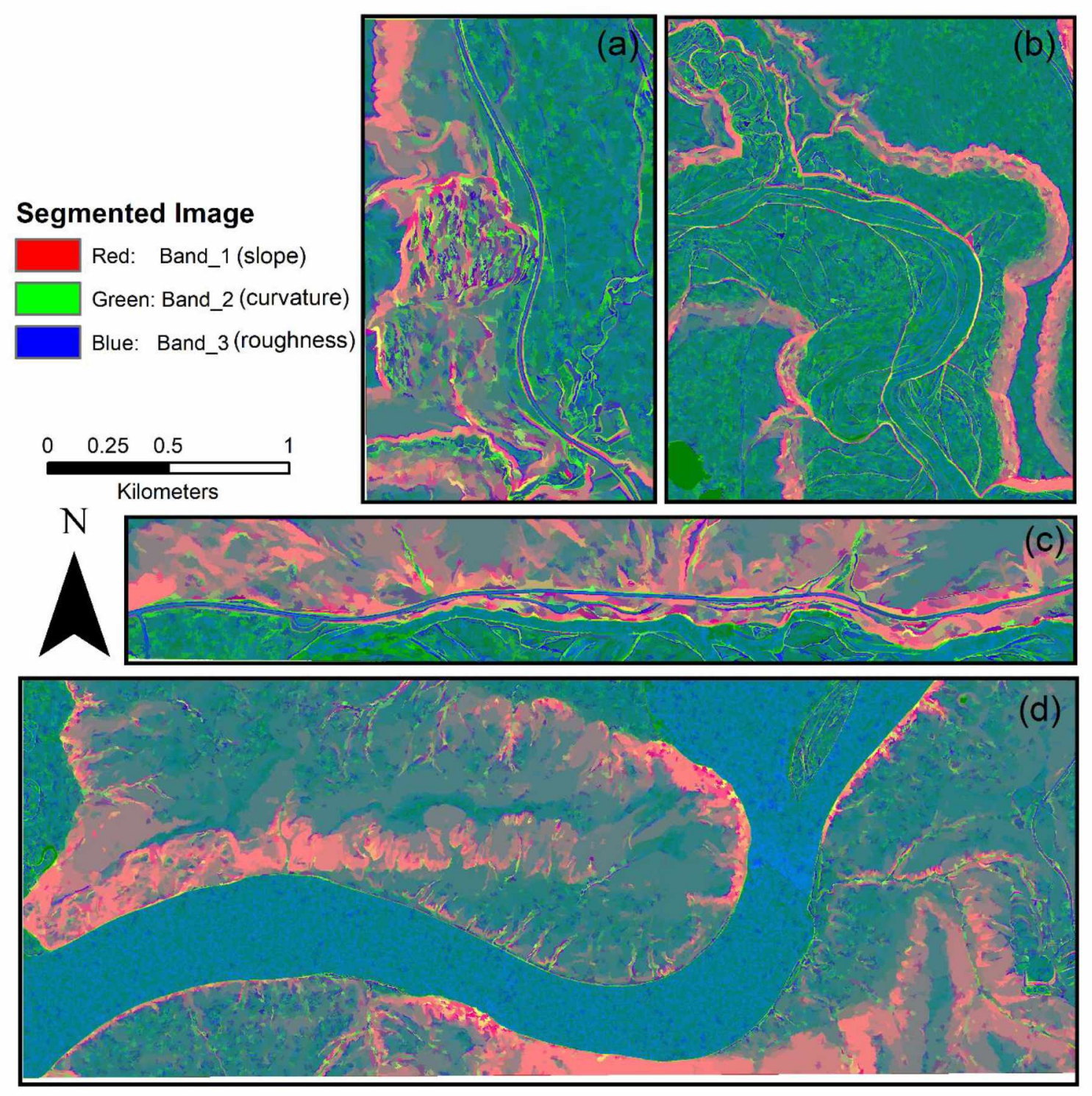

Figure 3.7: Segmented image generated from $1 \mathrm{~m}$ resolution LiDAR. Study sites are (a) Slate Creek, (b) Copper River, (c) Richardson, and (d) Yukon. 


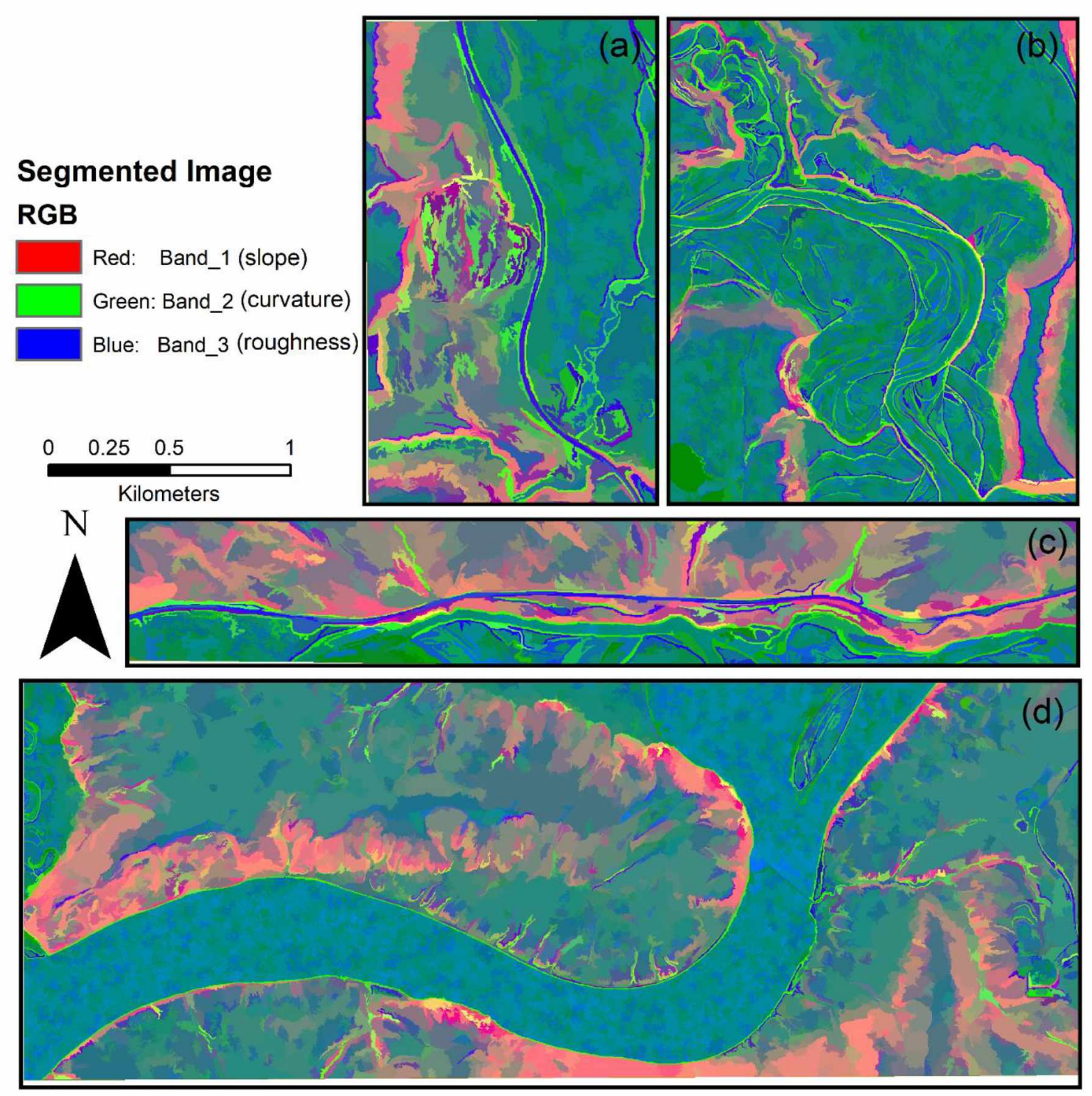

Figure 3.8: Segmented image from $2.5 \mathrm{~m}$ resolution LiDAR. Study sites are (a) Slate Creek, (b) Copper River, (c) Richardson, and (d) Yukon. 


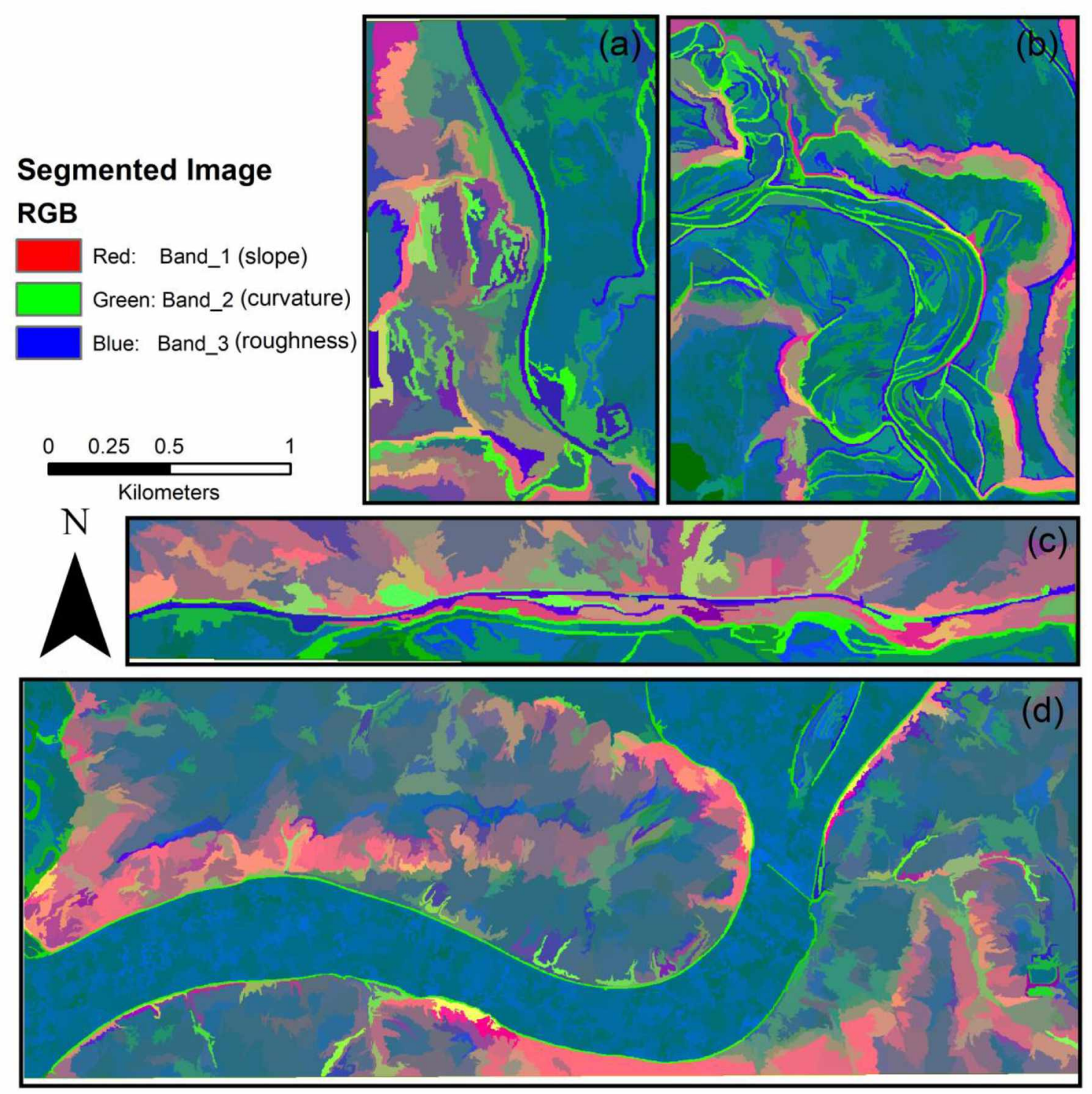

Figure 3.9: Segmented image from $5 \mathrm{~m}$ resolution LiDAR. Study sites are (a) Slate Creek, (b) Copper River, (c) Richardson, and (d) Yukon. 


\subsection{Training Samples}

After the segmented images were prepared, I extracted training samples into three categories: landslides, landslide susceptible, and stable. In this study, the phrase 'landslide susceptible' is used to define places where future landslides can occur, and the word 'landslide' is used to define locations of recent and/or historic landslides as determined by visual examination of the $1 \mathrm{~m}$ LiDAR DEM. The word 'stable' is used to define places that have a relatively flat slope. Water bodies and roads also are considered stable. This part is perhaps the most important step since the accuracy of the classified image will depend on how carefully the classifier has been trained. It also depends on the judgement of the person who is selecting the samples from the segmented images, which makes this process semi-automatic. I chose training samples as objects instead of individual pixels to follow the OOIA classification technique. In the study area, 21 objects were identified as landslides and 75 objects were identified as landslide susceptible locations. All other areas were designated as stable (Fig. 2.2). From this inventory, I chose 15 landslide objects, 57 landslide susceptible objects, and 52 stable objects for training (Fig. 3.10). In one instance, random samples were taken from the same landslide susceptible object instead of choosing the whole object as a training sample (Fig. 3.10a). This was done to avoid over sampling.

\subsection{Support Vector Machine (SVM) Classifier}

ArcGIS 10.5 offers a range of classifiers for image classification purposes. The SVM classifier is a well-known tool that uses machine learning algorithms. It requires a large amount of training samples, but the samples do not need to be normally 

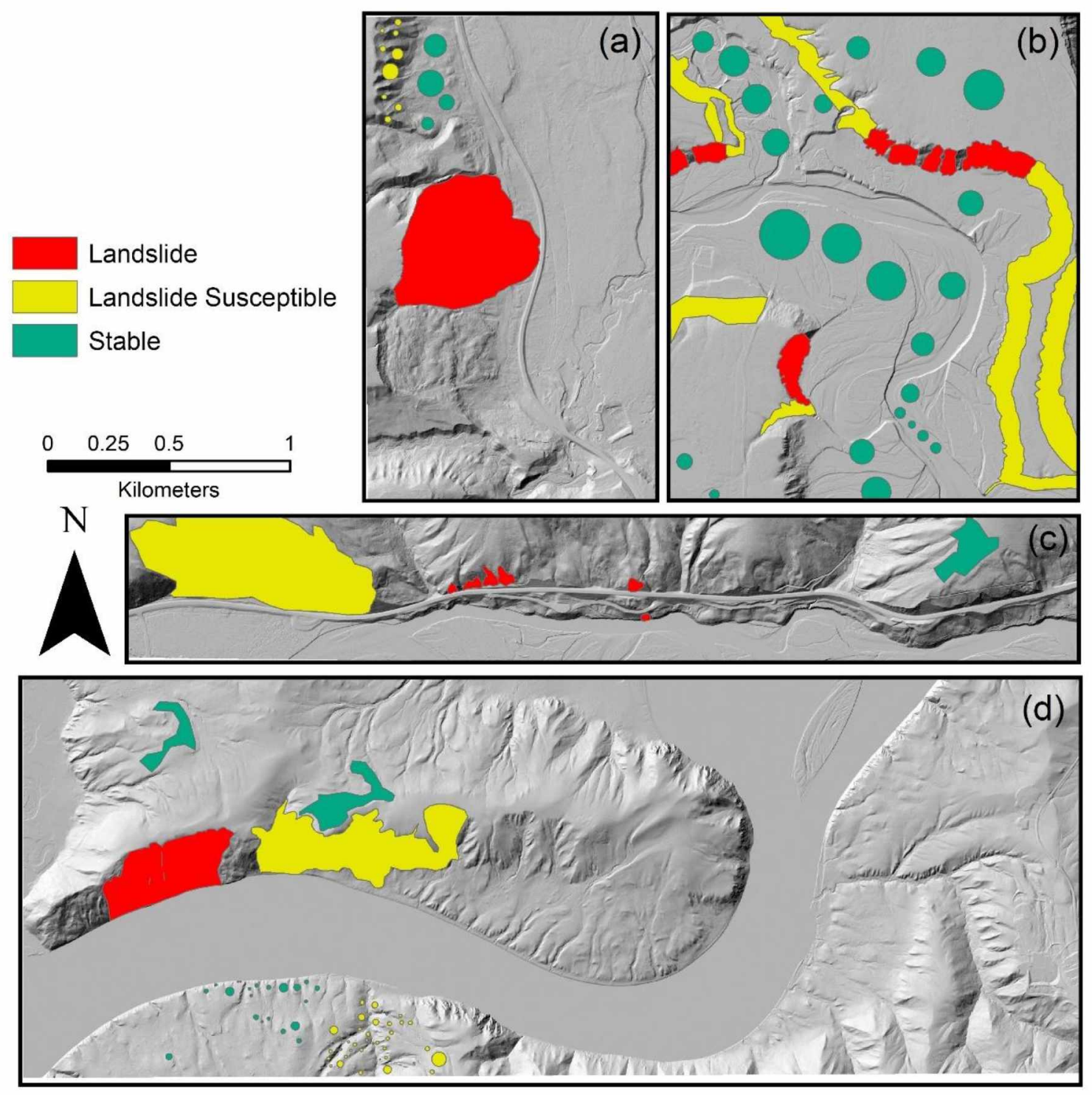

Figure 3.10: Training sample locations in the study area. Study sites are (a) Slate Creek, (b) Copper River, (c) Richardson, and (d) Yukon. 
distributed. I used this classifier to train the signature files, which then were used to classify the entire study area.

\subsection{Classified Image}

The classify raster function in ArcGIS 10.5 was used to generate classified images using the signature files. I implemented a generalization technique on the classified images to expand eight neighboring cells of the stable locations. Expanding helped to remove false positive pixels from the stable locations.

\subsection{Accuracy Assessment}

As with any image classification technique, accuracy assessment is an important measure to quantify the accuracy of a classification. At present, no standard evaluation method for assessing classified images from image segmentation exists (Drăguţ et al., 2011; Van Den Eeckhaut et al., 2012). I followed the same procedure used in traditional image classification techniques to quantify the accuracy.

The most common way to obtain accuracy is to compare classified points with referenced or ground-truthed points. This accuracy is calculated from a matrix or a table (known as a confusion matrix), where classified and referenced points are expressed as a tally of rows and columns, respectively (Table 3.2).

The major diagonal of the confusion matrix indicates the points that are correctly classified, and the overall accuracy of the classification is obtained by diving the sum of the major diagonal values by the total number of samples. As indicated in Table 3.2, the overall accuracy is $84 \%$. The accuracy of individual categories also is important as the individual category may exhibit drastically different accuracies but all of them are 
Table 3.2: Sample confusion matrix table

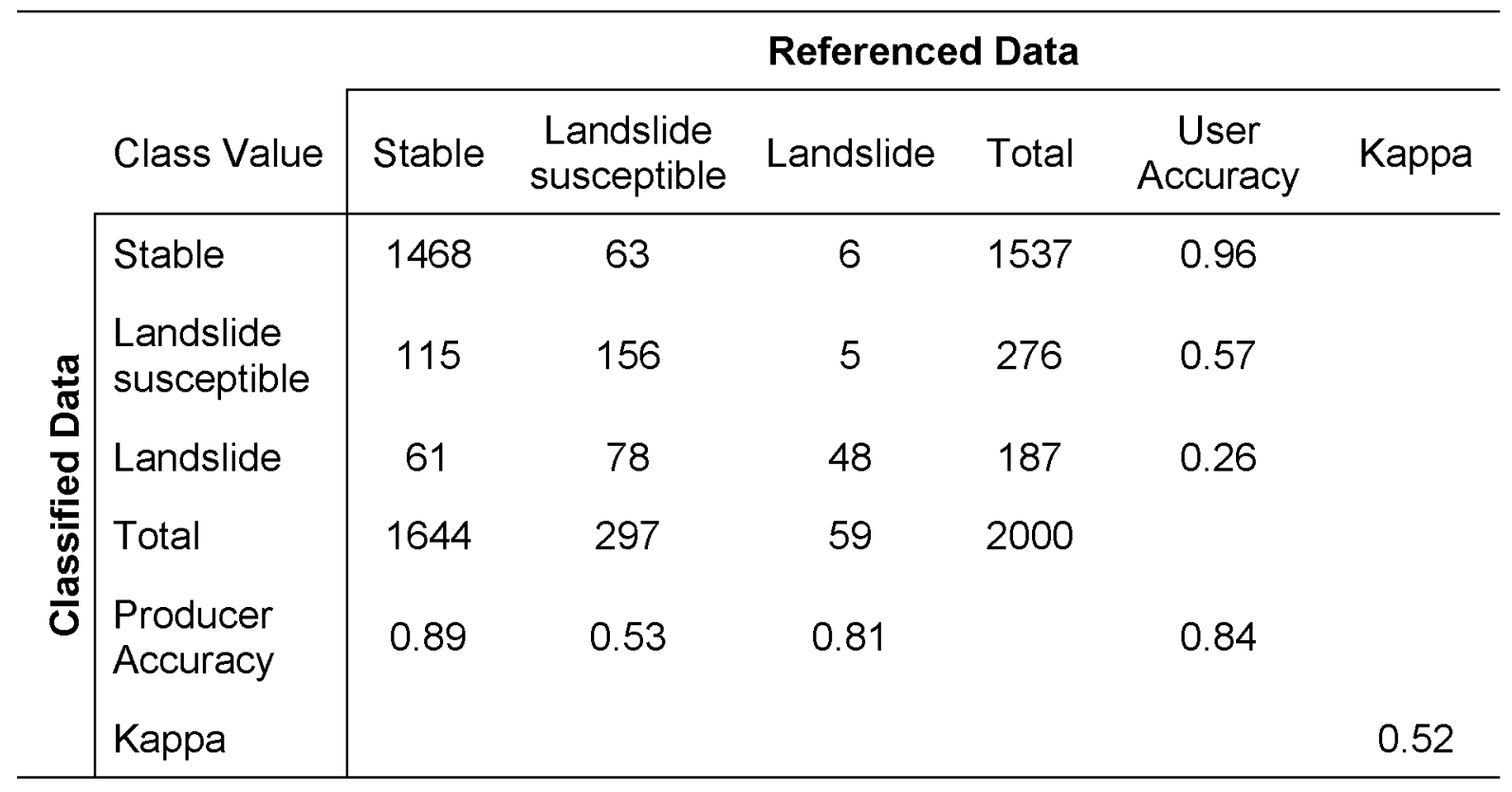


combined to determine the overall accuracy; hence, overall accuracy may be misleading in interpreting a classified image.

There are at least two ways to determine individual categories:

i) Producer's Accuracy: This is obtained by dividing the total number of correctly classified data for a category by the total number of ground-truthed points in that category. It is important to remember that the total number of correctly classified data for each category is presented by each diagonal element in the error matrix. It is called producer's accuracy as the producer of an image or map is concerned about how well a certain category on the ground can be classified (Congalton, 1991). The results of this analysis provide a producer's accuracy of $89 \%, 53 \%$, and $81 \%$ for stable, landslide susceptible, and landslide locations, respectively.

ii) User's Accuracy: This is obtained by dividing the total number of correctly classified data for a category by the total number of classified data sampled in that category. User's accuracy deals with commission error, which is when other categories represent false positives. User's accuracy represents how well a map represents the original ground. A better name for this value is "reliability" (Congalton, 1991; Story and Congalton, 1986). For this study, the user's accuracy is $96 \%, 57 \%$, and $26 \%$ for stable, landslide susceptible, and landslide locations, respectively.

These two accuracies produce different results and the interpretation of their meaning is different. Producer's accuracy considers the omission error, which is that ground-truthed points are not correctly classified in their categories and are omitted from those categories. On the other hand, users of a map trying to find a specific location on a map generally expect to find the same location on the ground; however, 
this is often not the case. A user can find a landslide location on the map, but he or she may not find a landslide at that location in the real world.

Another measure of accuracy is kappa analysis (Congalton et al.1983). It is often used in remotely-sensed data. The kappa analysis generates a statistic called KHAT, which measures the agreement between referenced and classified data. KHAT values greater than $80 \%$, between $40 \%$ and $80 \%$, and less than $40 \%$ indicate strong, moderate, or poor agreement, respectively, between classified and referenced data (ESRI, 2017). In Table 3.2, the KHAT or Kappa value is $52 \%$, indicating moderate agreement.

In this study, I assessed the accuracy of 3,000 randomly generated points, using the stratified random function. This function generates points that are proportional to the relative area of each class (e.g., landslide, stable). Since stable locations had the highest proportion, these areas contained the highest number of random points. 


\section{Chapter 4 Results and Discussion}

Fig. $4.1,4.2$, and 4.3 are the classified images from the $1 \mathrm{~m}, 2.5 \mathrm{~m}$, and $5 \mathrm{~m}$ segmented images, respectively, which all incorporated the NDVI. Fig. 4.4, 4.5, and 4.6 are the classified images from the $1 \mathrm{~m}, 2.5 \mathrm{~m}$, and $5 \mathrm{~m}$ segmented images without the NDVI, respectively. From visual inspection of the classified images, the finer resolution 1m classified image with NDVI (Fig. 4.1) delineated landslide objects better than the coarser resolution $2.5 \mathrm{~m}$ and $5 \mathrm{~m}$; however, it also produced more false positives that led to low user accuracy. At the other extreme, the $5 \mathrm{~m}$ classified image without NDVI did not identify any landslide objects, with all landslide locations identified as landslide susceptible (Fig. 4.6). This may be attributed to the over sampling of training samples as landslide susceptible pixels. Overall, the addition of NDVI produced better results, and the $5 \mathrm{~m}$ resolution LiDAR with NDVI generated less false positives than the $1 \mathrm{~m}$ and $2.5 \mathrm{~m}$ scales. Note that I used the same training samples for all scales.

Tables 4.1 through 4.6 summarize the accuracy assessment results for the $1 \mathrm{~m}$, $2.5 \mathrm{~m}$, and $5 \mathrm{~m}$ resolution classified images with and without NDVI. Table 4.7 summarizes overall accuracy and kappa statistics for the $1 \mathrm{~m}, 2.5 \mathrm{~m}$, and $5 \mathrm{~m}$ resolution LiDAR data, and Tables 4.8 through 4.10 summarize producer and user accuracy for landslide, landslide susceptible, and stable locations, respectively. The overall accuracy of $1 \mathrm{~m}, 2.5 \mathrm{~m}$, and $5 \mathrm{~m}$ resolution classified images varies between $80 \%$ and $83 \%$ with the highest accuracy obtained from the $5 \mathrm{~m}$ resolution image with $\mathrm{NDVI}$, and the lowest accuracy from the $1 \mathrm{~m}$ resolution LiDAR without NDVI (Table 4.7). The high overall accuracy at each scale may be attributed to the fact that the majority of the accuracy assessment points were generated in stable locations that were correctly classified. 

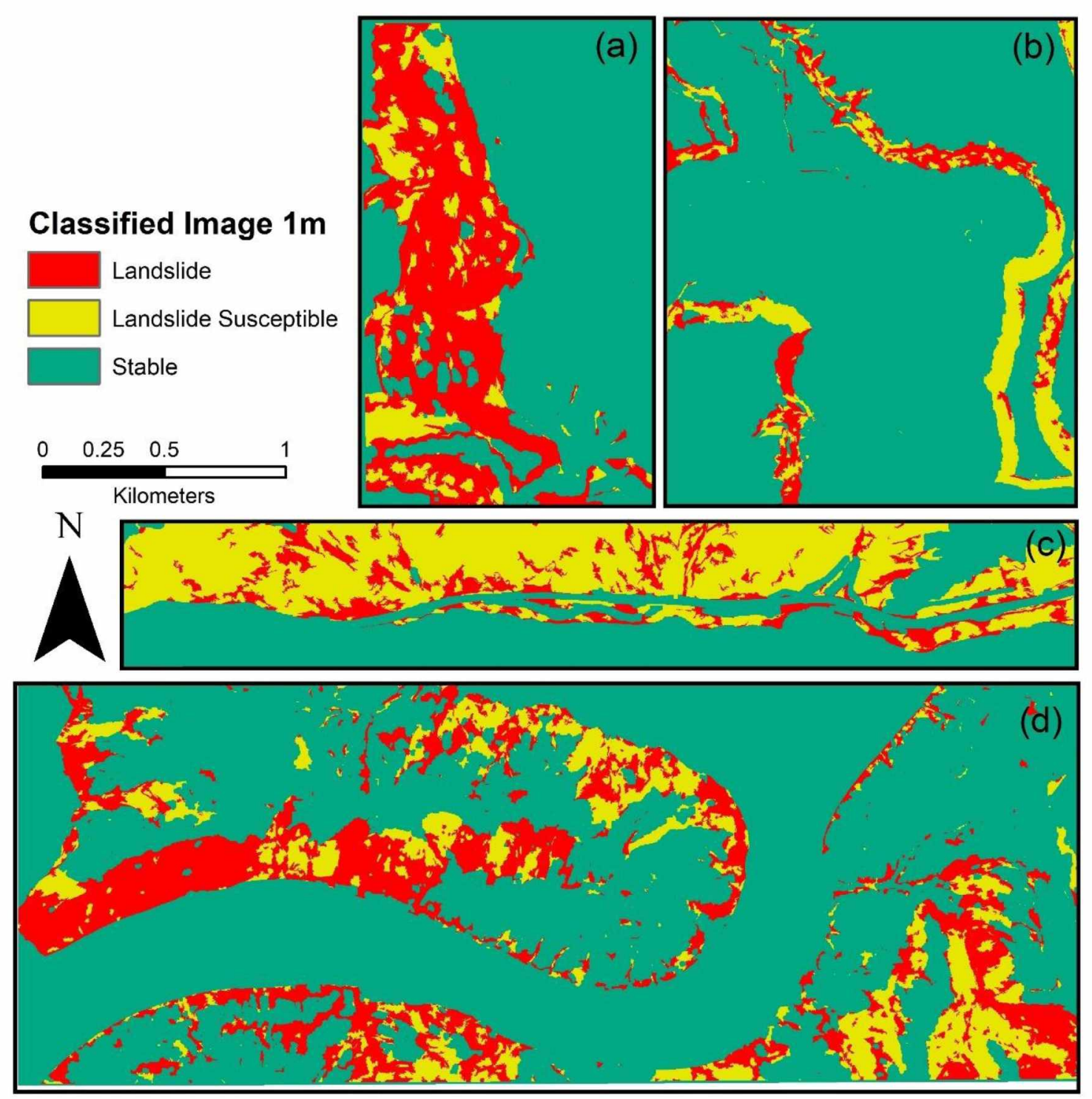

Figure 4.1: Classified Image from $1 \mathrm{~m}$ resolution LiDAR with NDVI. Study sites are (a) Slate Creek, (b) Copper River, (c) Richardson, and (d) Yukon. 

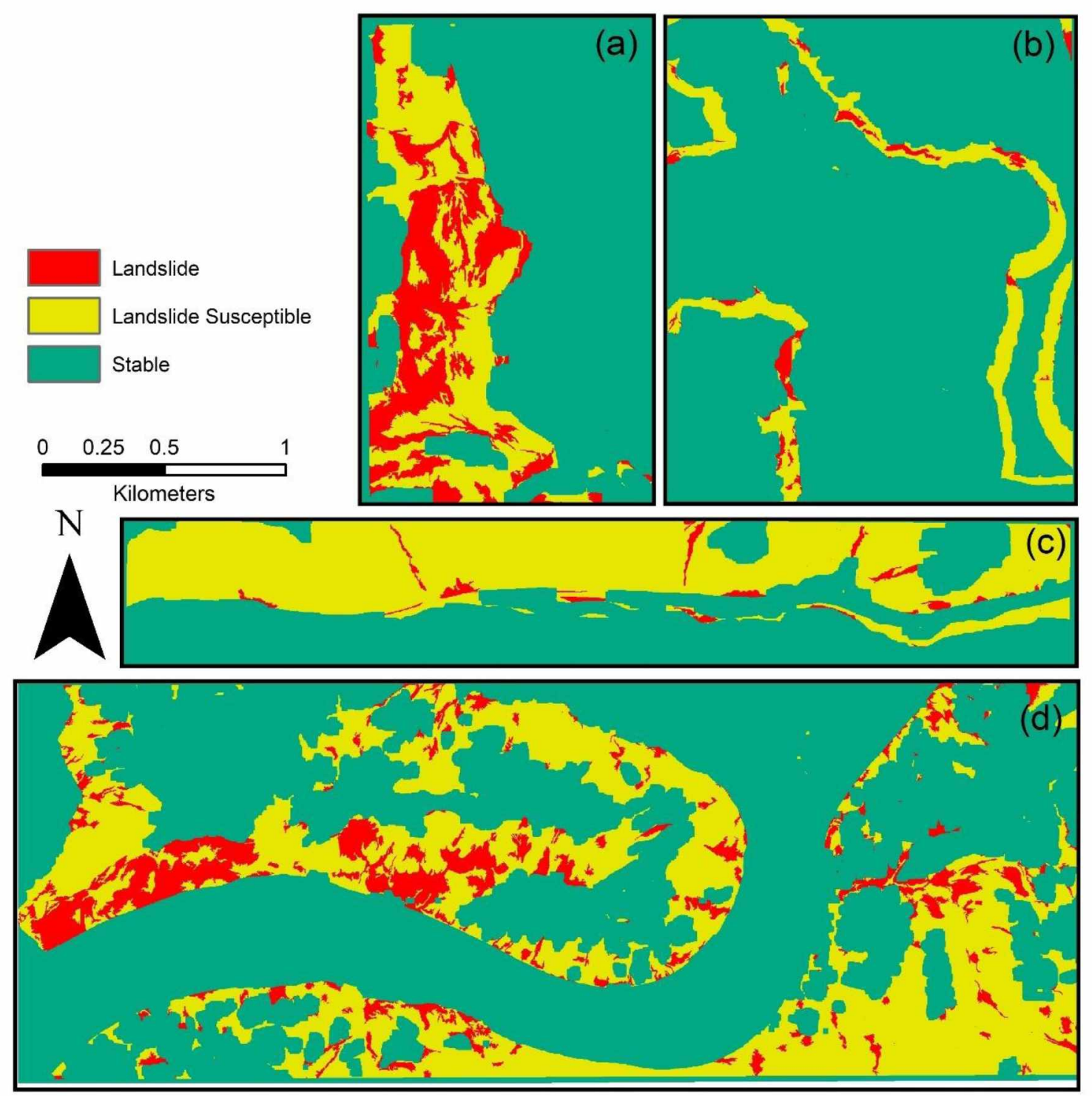

Figure 4.2: Classified Image from $2.5 \mathrm{~m}$ resolution LiDAR with NDVI. Study sites are (a) Slate Creek, (b) Copper River, (c) Richardson, and (d) Yukon. 


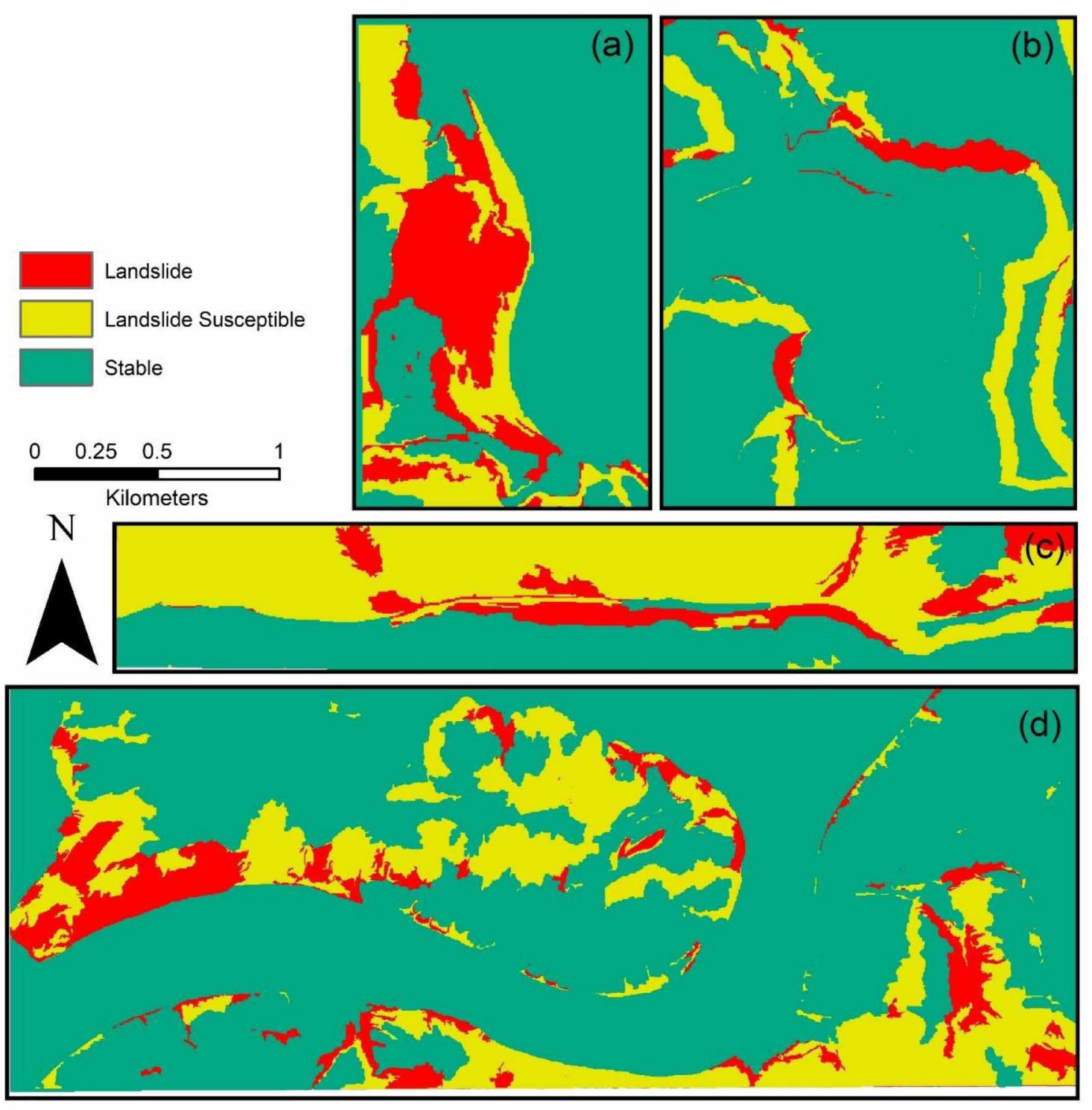

Figure 4.3: Classified Image from $5 \mathrm{~m}$ resolution LiDAR with NDVI. Study sites are (a) Slate Creek, (b) Copper River, (c) Richardson, and (d) Yukon. 

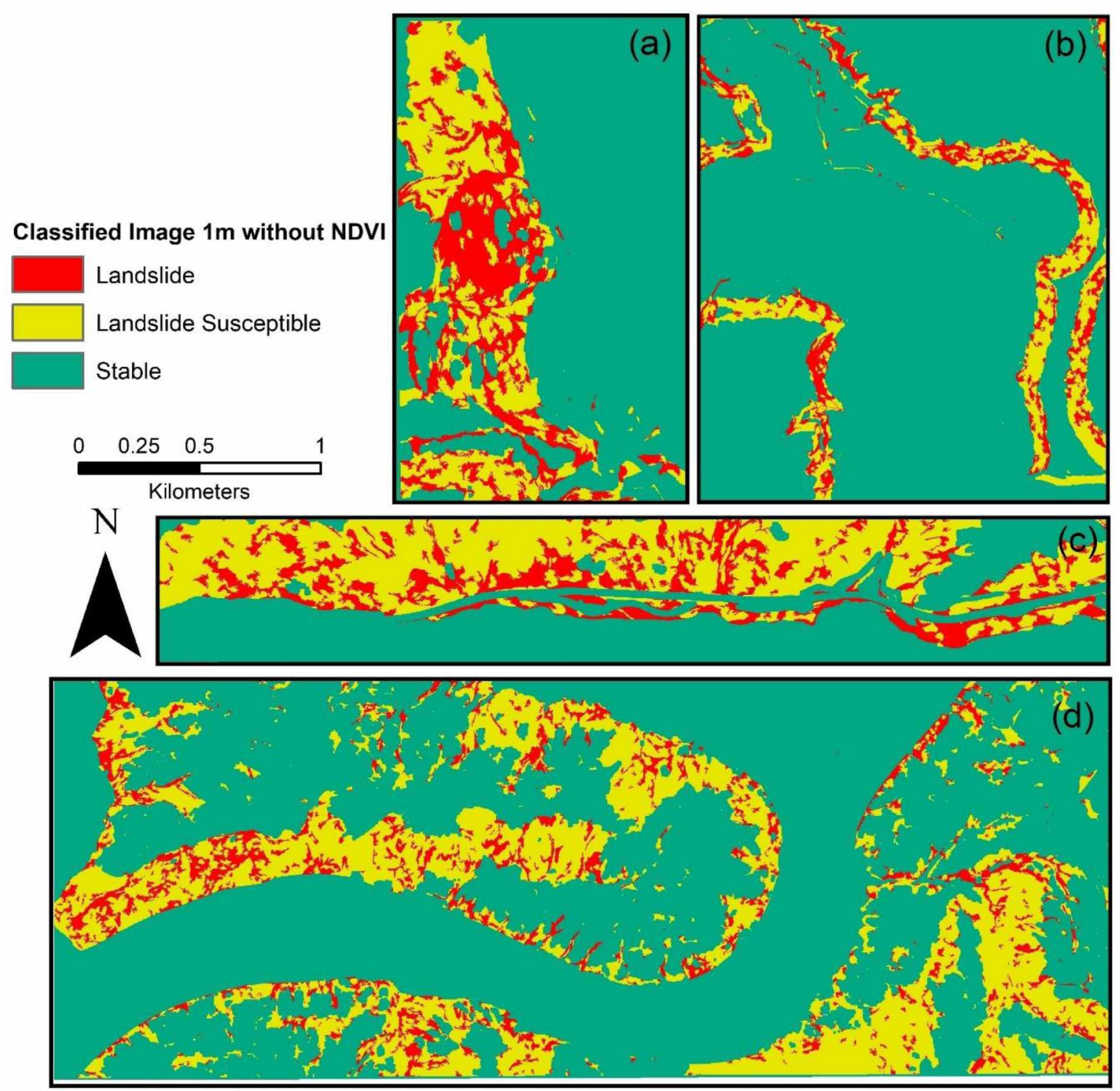

Figure 4.4: Classified image from $1 \mathrm{~m}$ resolution LiDAR without NDVI. Study sites are (a) Slate Creek, (b) Copper River, (c) Richardson, and (d) Yukon. 


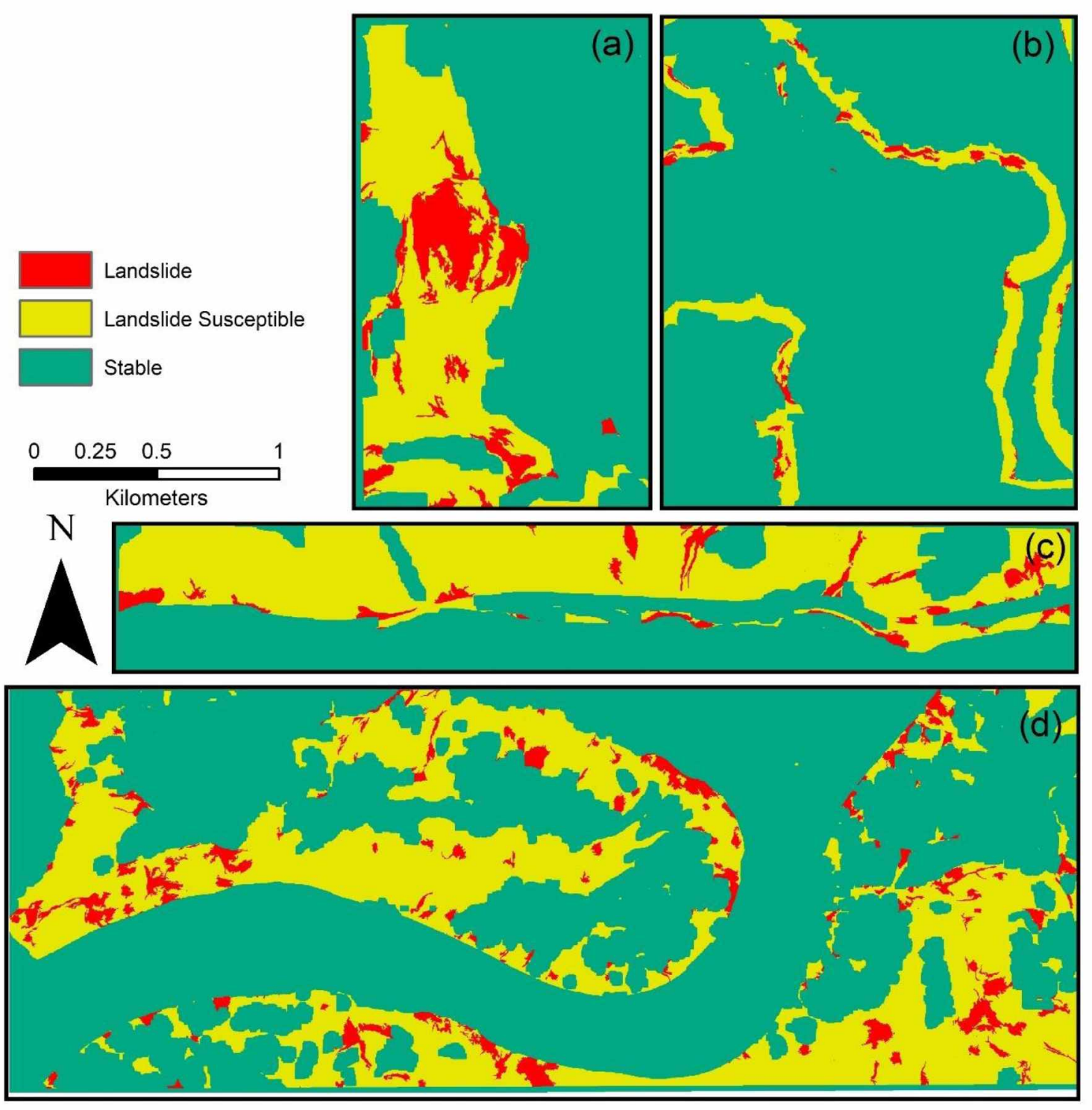

Figure 4.5: Classified Image from 2.5m resolution LiDAR without NDVI. Study sites are (a) Slate Creek, (b) Copper River, (c) Richardson, and (d) Yukon. 

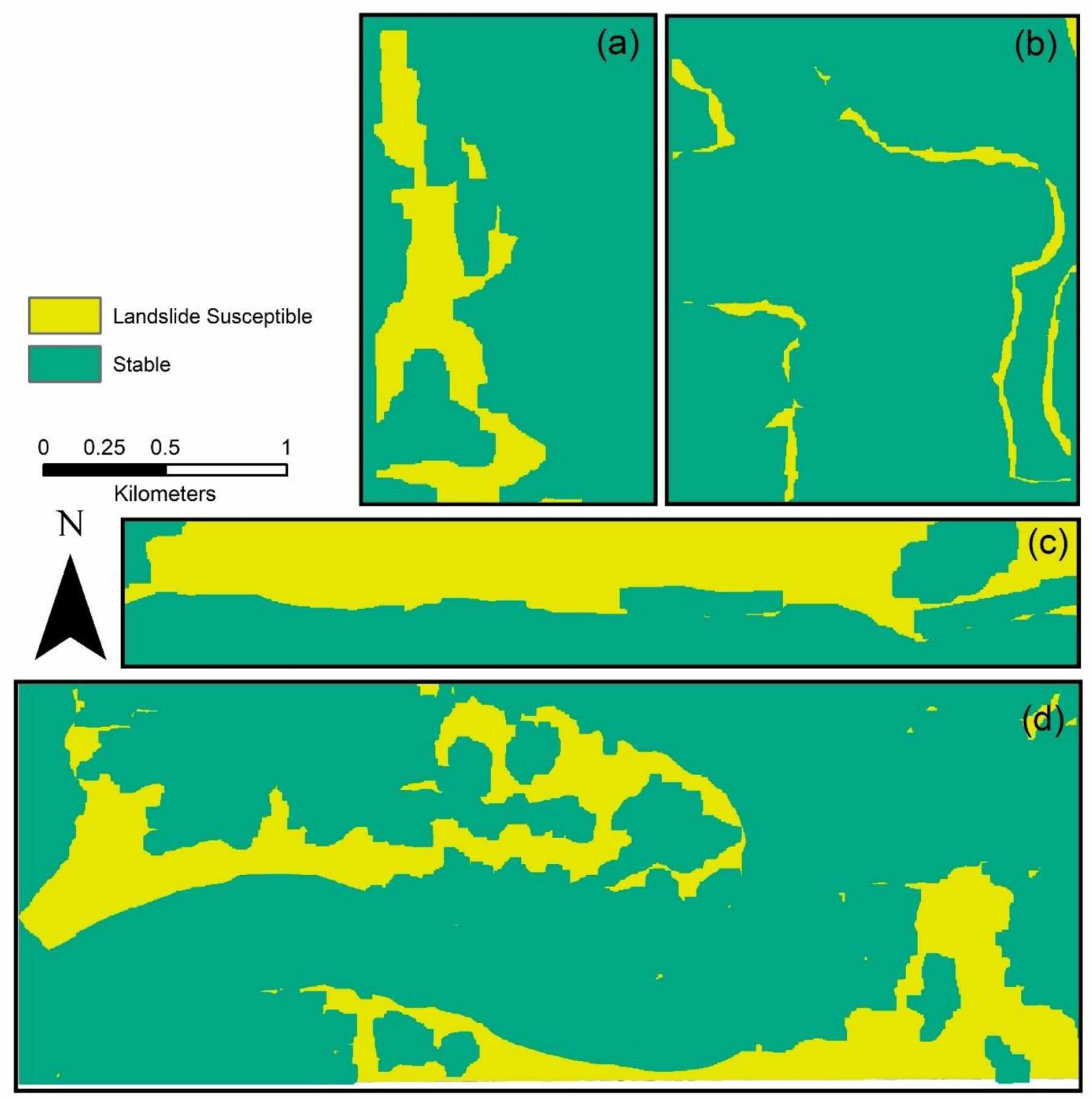

Figure 4.6: Classified image from 5m resolution LiDAR without NDVI. Study sites are (a) Slate Creek, (b) Copper River, (c) Richardson, and (d) Yukon. 
Table 4.1: Confusion matrix table for $1 \mathrm{~m}$ resolution LiDAR with NDVI

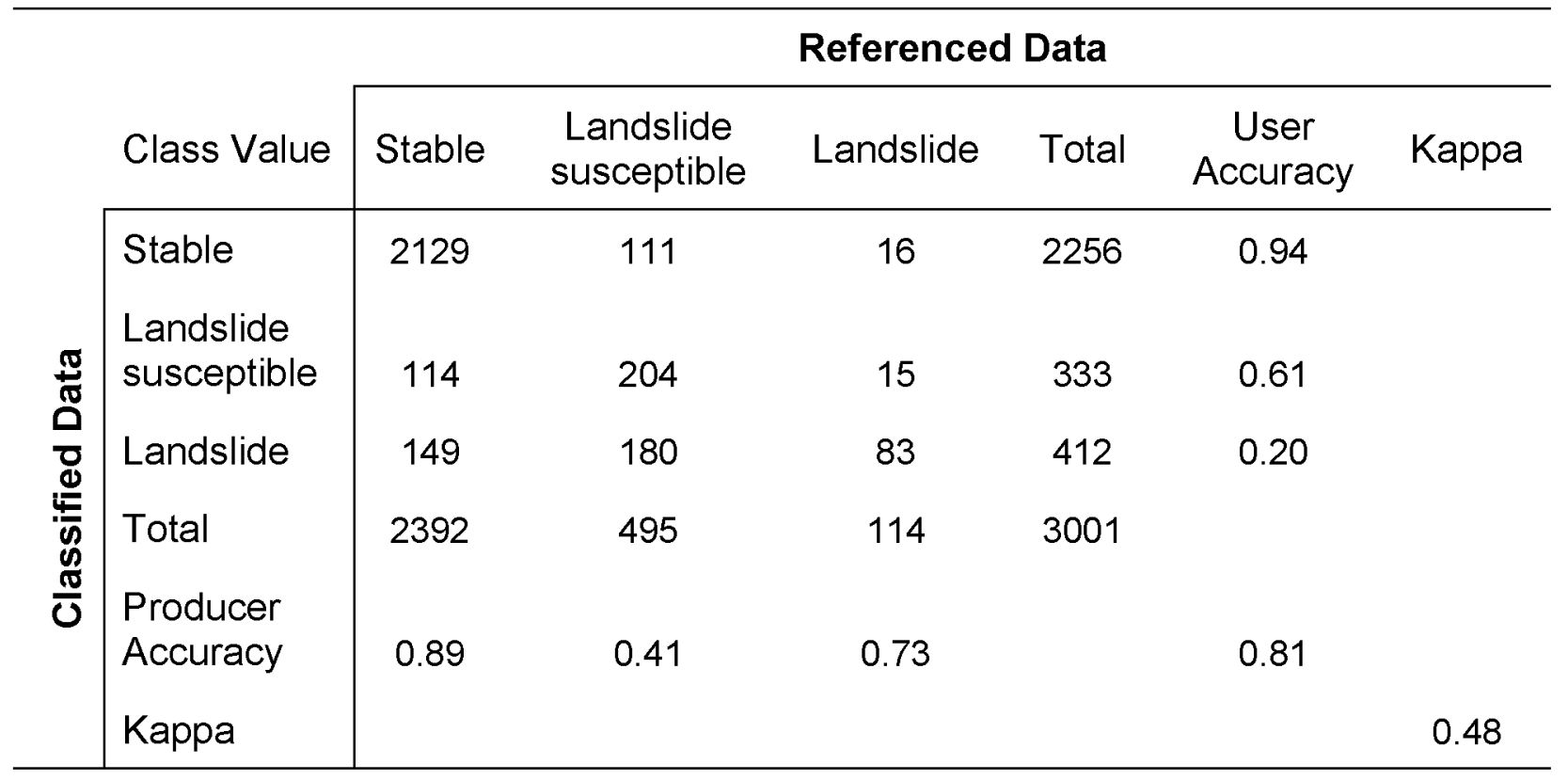

Table 4.2: Confusion matrix table for $1 \mathrm{~m}$ resolution LiDAR without NDVI

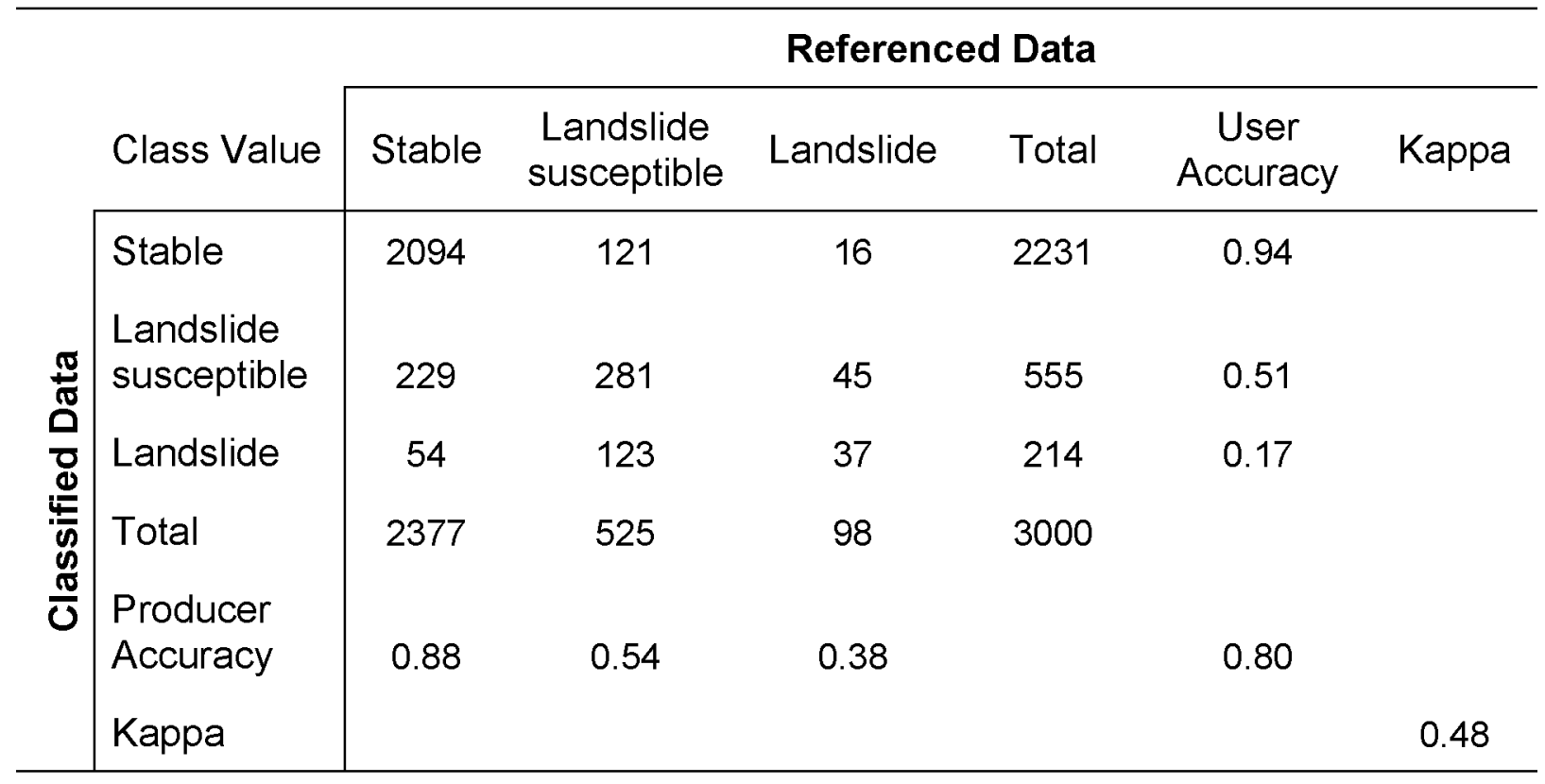


Table 4.3: Confusion matrix table for $2.5 \mathrm{~m}$ resolution LiDAR with NDVI

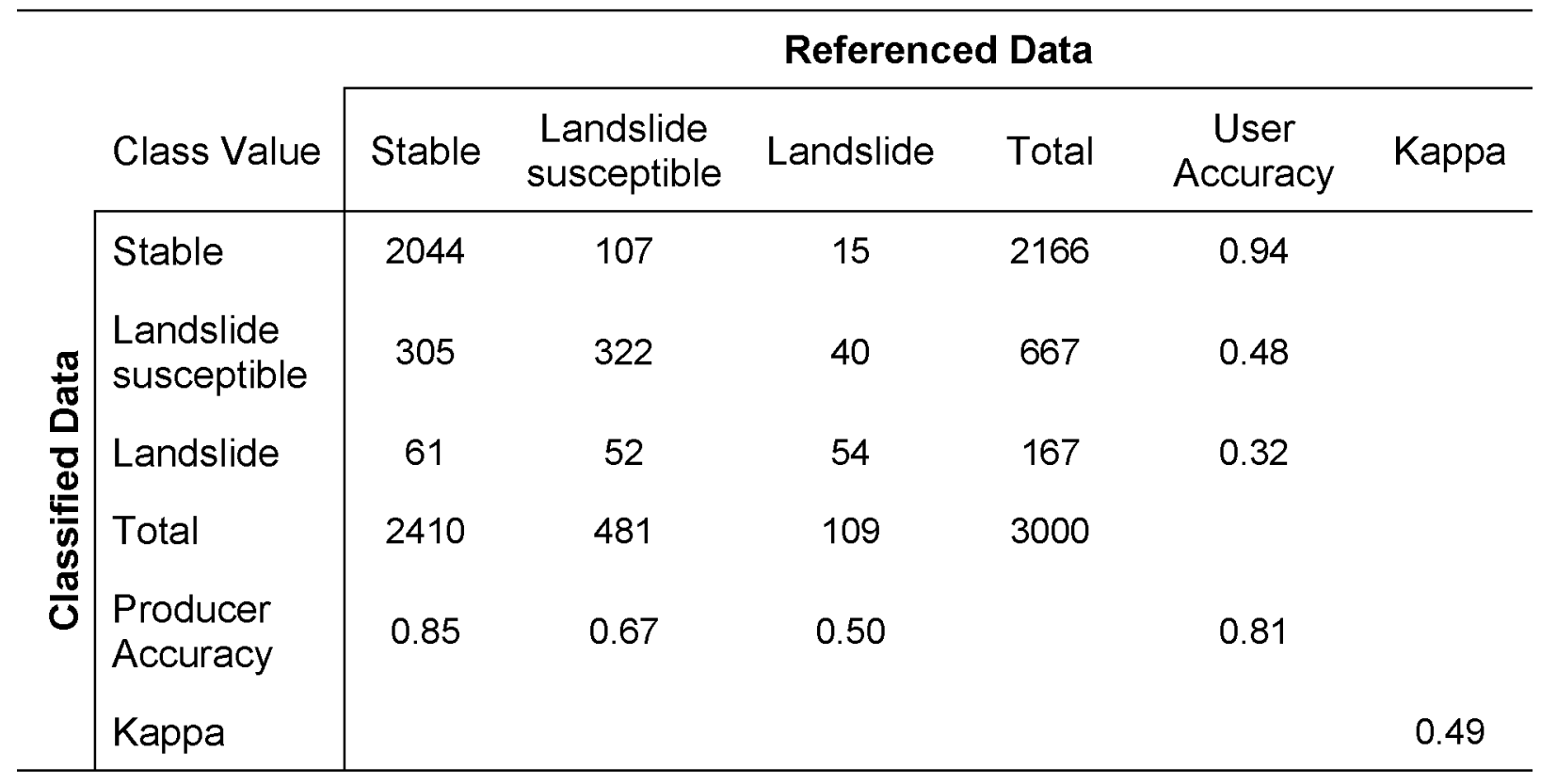

Table 4.4: Confusion matrix table for $2.5 \mathrm{~m}$ resolution LiDAR without NDVI

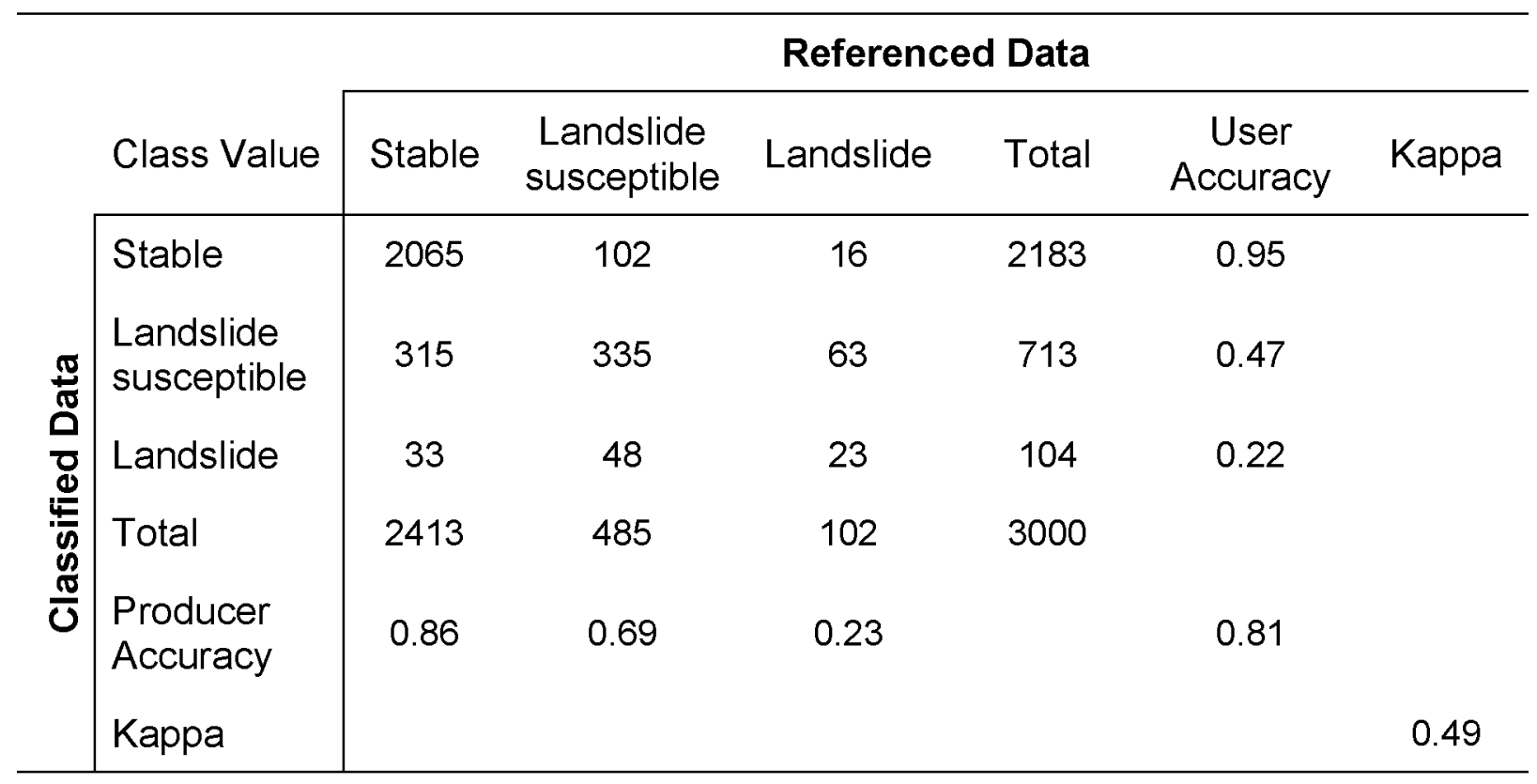


Table 4.5: Confusion matrix table for $5 \mathrm{~m}$ resolution LiDAR with NDVI

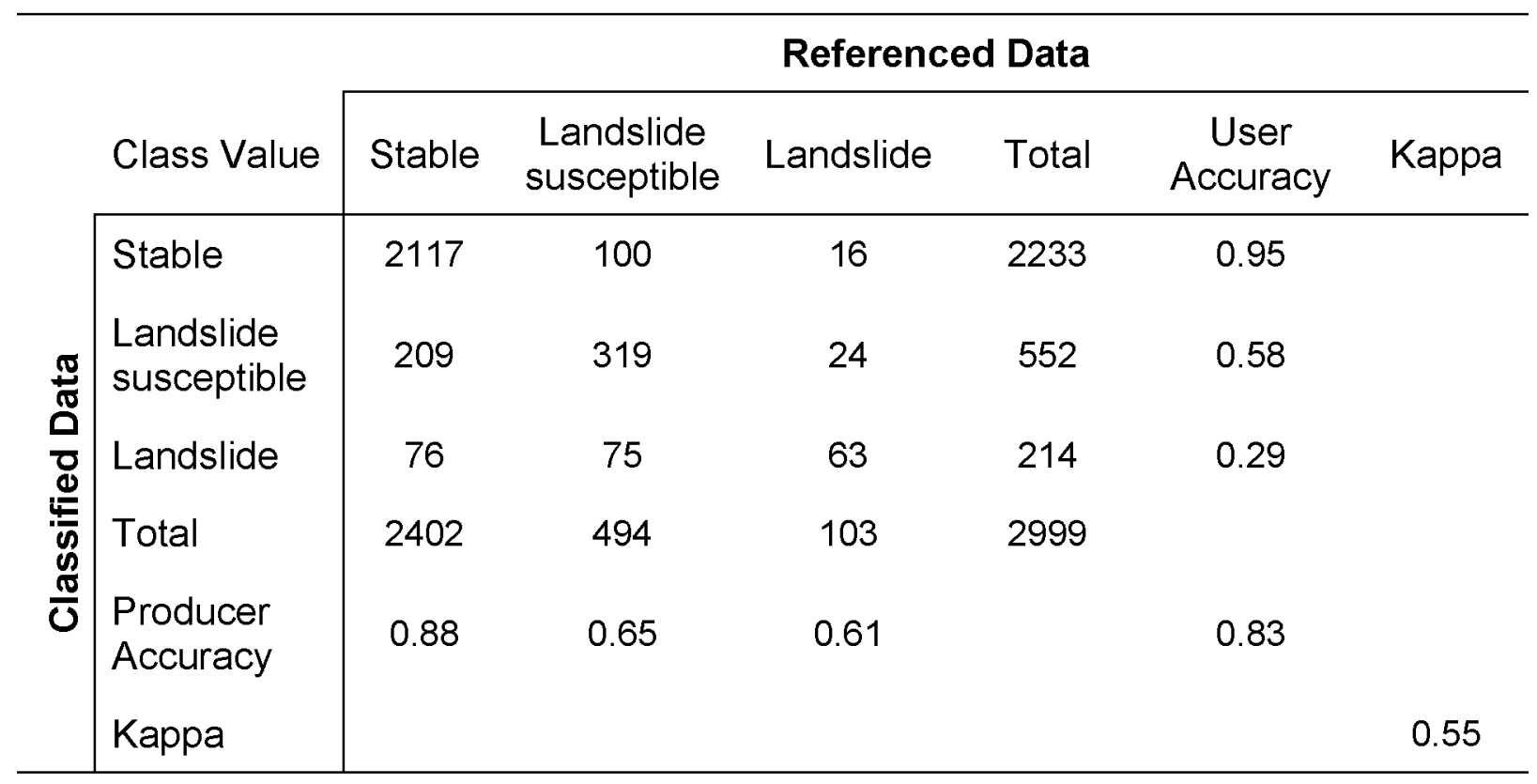

Table 4.6: Confusion matrix table for $5 \mathrm{~m}$ resolution LiDAR without NDVI

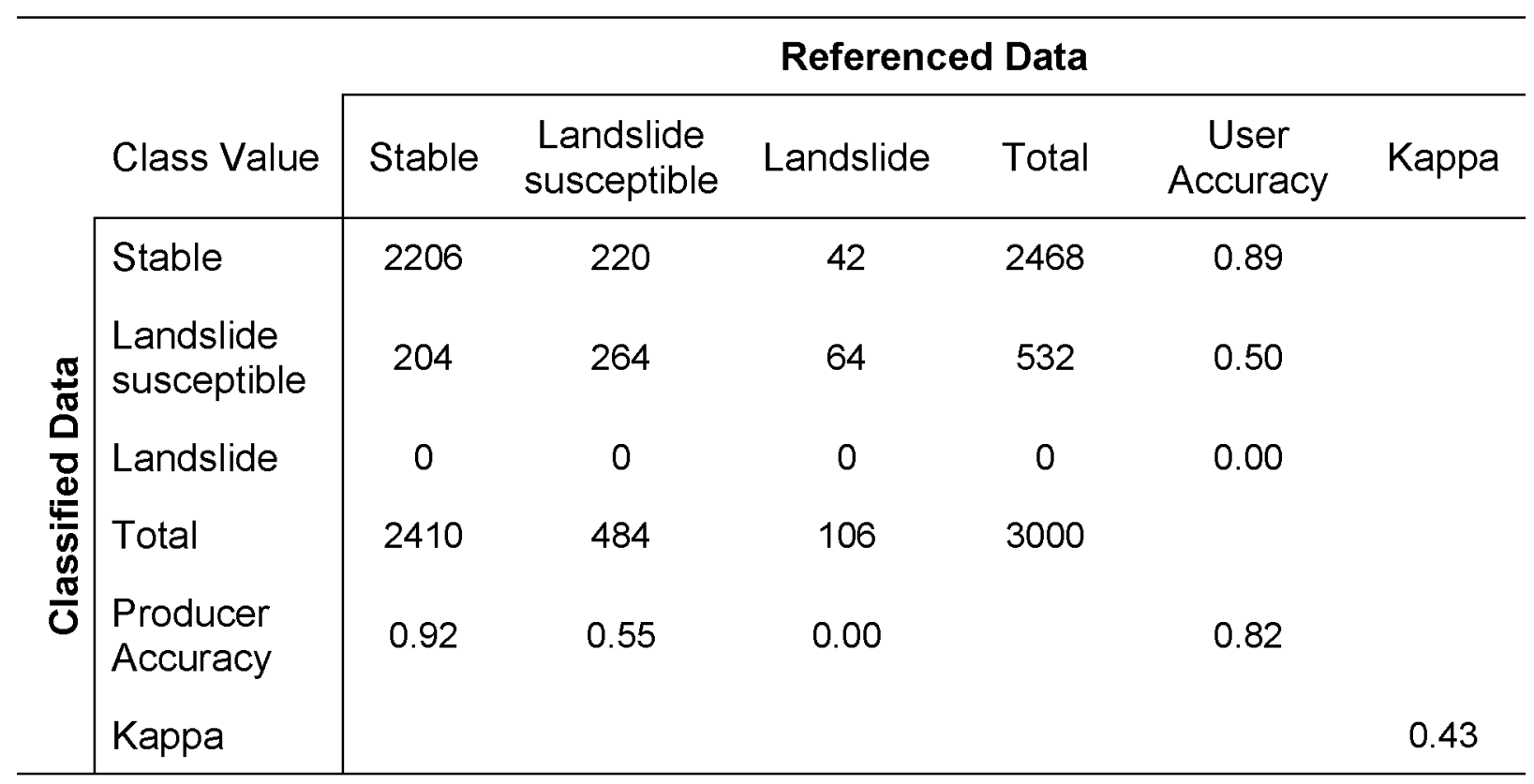


Table 4.7: Summary of overall accuracy and kappa statistics for multi-resolution LiDAR data

\begin{tabular}{lcccc}
\hline Scale & \multicolumn{2}{c}{ NDVI } & \multicolumn{2}{c}{ Without NDVI } \\
& $\begin{array}{c}\text { Overall } \\
\text { Accuracy }\end{array}$ & Kappa & $\begin{array}{c}\text { Overall } \\
\text { Accuracy }\end{array}$ & Kappa \\
\hline LiDAR 1m & 0.81 & 0.48 & 0.80 & 0.48 \\
LiDAR 2.5m & 0.81 & 0.49 & 0.81 & 0.49 \\
LiDAR 5m & 0.83 & 0.55 & 0.82 & 0.43 \\
\hline
\end{tabular}


Table 4.8: Summary of producer accuracy and user accuracy in landslide locations for multi-resolution LiDAR data

NDVI

\section{Scale}

LiDAR $1 \mathrm{~m}$

LiDAR 2.5m

LiDAR 5m
Producer accuracy
User accuracy

0.20

0.32

0.29

\section{Without NDVI}

Producer accuracy

0.38

0.23

0.00
User accuracy

0.17

0.22

0.00

Table 4.9: Summary of producer accuracy and user accuracy in landslide susceptible locations for multi-resolution LiDAR data

\begin{tabular}{lcccc}
\hline \multirow{2}{*}{ Scale } & \multicolumn{2}{c}{ NDVI } & \multicolumn{2}{c}{ Without NDVI } \\
& $\begin{array}{r}\text { Producer } \\
\text { accuracy }\end{array}$ & User accuracy & $\begin{array}{c}\text { Producer } \\
\text { accuracy }\end{array}$ & User accuracy \\
\hline LiDAR 1m & 0.41 & 0.61 & 0.54 & 0.51 \\
LiDAR 2.5m & 0.67 & 0.48 & 0.69 & 0.47 \\
LiDAR 5m & 0.65 & 0.58 & 0.55 & 0.50 \\
\hline
\end{tabular}

Table 4.10: Summary of producer accuracy and user accuracy in stable locations for multi-resolution LiDAR data

\begin{tabular}{lcccc}
\hline \multirow{2}{*}{ Scale } & \multicolumn{2}{c}{ NDVI } & \multicolumn{2}{c}{ Without NDVI } \\
& $\begin{array}{l}\text { Producer } \\
\text { accuracy }\end{array}$ & User accuracy & $\begin{array}{c}\text { Producer } \\
\text { accuracy }\end{array}$ & User accuracy \\
\hline LiDAR 1m & 0.89 & 0.94 & 0.88 & 0.94 \\
LiDAR 2.5m & 0.85 & 0.94 & 0.86 & 0.95 \\
LiDAR 5m & 0.88 & 0.95 & 0.92 & 0.89 \\
\hline
\end{tabular}


(Tables 4.1 through 4.6); however, the overall accuracy was not a good indicator of how landslide and landslide susceptible locations were correctly classified.

The highest kappa value, 55\%, was obtained from the $5 \mathrm{~m}$ resolution LiDAR with $\mathrm{NDVI}$, and the lowest kappa value of $43 \%$ was obtained from the $5 \mathrm{~m}$ resolution LiDAR without NDVI. The $1 \mathrm{~m}$ and $2.5 \mathrm{~m}$ resolution classified images generated kappa values of $48 \%$ and $49 \%$, respectively, for both with and without NDVI (Table 4.7 ).

Producer and user accuracies provided a good indication of landslide and landslide susceptible locations in this accuracy assessment. The additional NDVI input generated better results in every instance of landslide identification. The $1 \mathrm{~m}$ scale LiDAR with NDVI generated a producer accuracy of $73 \%$ for landslide locations, whereas the same scale LiDAR without the addition of NDVI generated a producer accuracy of only $38 \%$. Similarly, the $2.5 \mathrm{~m}$ LiDAR with NDVI generated a user accuracy of $32 \%$, and without NDVI generated a user accuracy of only $22 \%$ in identifying landslide locations (Table 4.8). Overall, the addition of NDVI yielded better results in user accuracy. The proposed method generally performed better in identifying landslide susceptible locations (resulting in higher producer and user accuracy) than for identifying landslide locations as discussed above (Table 4.9). The highest producer and user accuracies were obtained for stable locations (Table 4.10). For example, a user accuracy of $95 \%$ was achieved in identifying stable locations in both the $5 \mathrm{~m}$ resolution LiDAR with NDVI and the $2.5 \mathrm{~m}$ resolution LiDAR without NDVI. In general, the addition of NDVI with segmented images from slope, profile curvature, and roughness yielded better results in identifying landslide locations. 
I combined the $1 \mathrm{~m}, 2.5 \mathrm{~m}$, and $5 \mathrm{~m}$ resolution classified images with NDVI (Fig. 4.1 to 4.3 ) using the raster calculator to generate a combined classification map (Fig. 4.7). For each individual classified image, I assigned pixels in landslide, landslide susceptible, and stable locations values of 2,1 , and 0 , respectively. Through raster addition, this resulted in a combined map with six class values. The class value of 6 means that the place (or pixel) was identified as a landslide at all three scales. A class value of 5 indicates that the place was identified as a landslide in two instances, but at one instance it was identified as landslide susceptible. The class value of 4 represents a place identified as a landslide at least one time. A class value of 3 means that the place was identified as either landslide susceptible at all three scales, or identified as a landslide, landslide susceptible, or as stable at all three scales. A class value of 2 means that the place was identified as either a landslide in one instance and stable at two other scales, or landslide susceptible at two scales and stable in one other instance. A class value of 1 means that the place was identified as landslide susceptible in one instance and stable at two other scales. Finally, a class value of 0 indicates a place identified as stable at all three scales (Fig. 4.7).

Next, I reclassified the combined map in Fig. 4.7 into a new map using only three classes (as specified in Table 4.11), where the values 2, 1, and 0 represent landslide, landslide susceptible, and stable locations, respectively (Fig. 4.8). I conducted an accuracy assessment on the combined classified image to generate a confusion matrix (Table 4.12).

I used the same procedure for the $1 \mathrm{~m}, 2.5 \mathrm{~m}$, and $5 \mathrm{~m}$ resolution classified images without NDVI (Fig. 4.4 to Fig. 4.6). Fig. 4.9 is the combined classification map. This map 

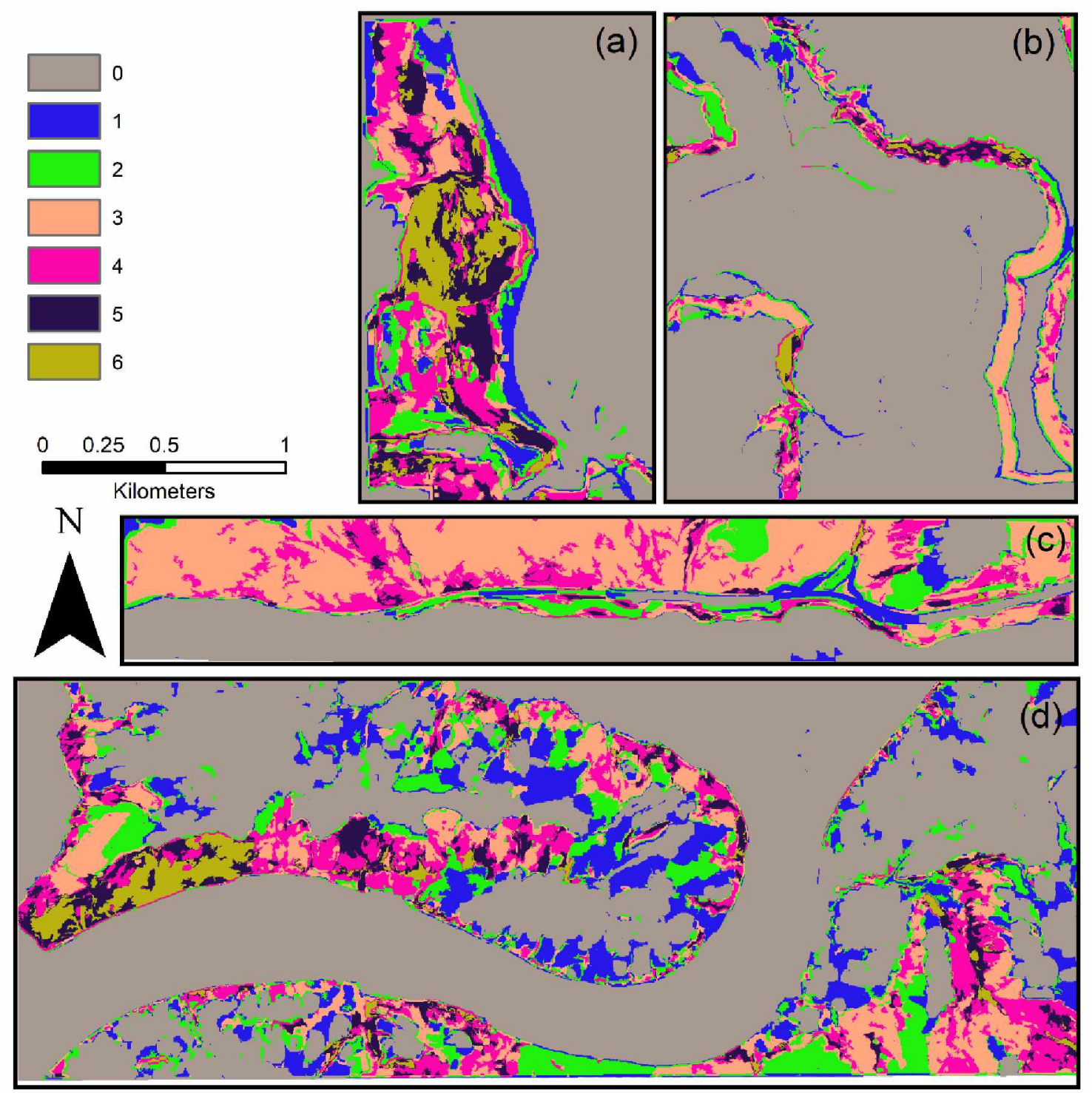

Figure 4.7: Combined classification map from $1 \mathrm{~m}, 2.5 \mathrm{~m}$, and $5 \mathrm{~m}$ resolution classified images with NDVI. Study sites are (a) Slate Creek, (b) Copper River, (c) Richardson, and (d) Yukon. 
Table 4.11: Reclassified values of the combined image from Fig. 4.7

\begin{tabular}{cc}
\hline Class values in combined image & New values in the reclassified image \\
\hline 0 & 0 \\
1 & \\
2 & 1 \\
3 & \\
4 & 2 \\
\hline 5 & \\
6 & \\
\hline
\end{tabular}



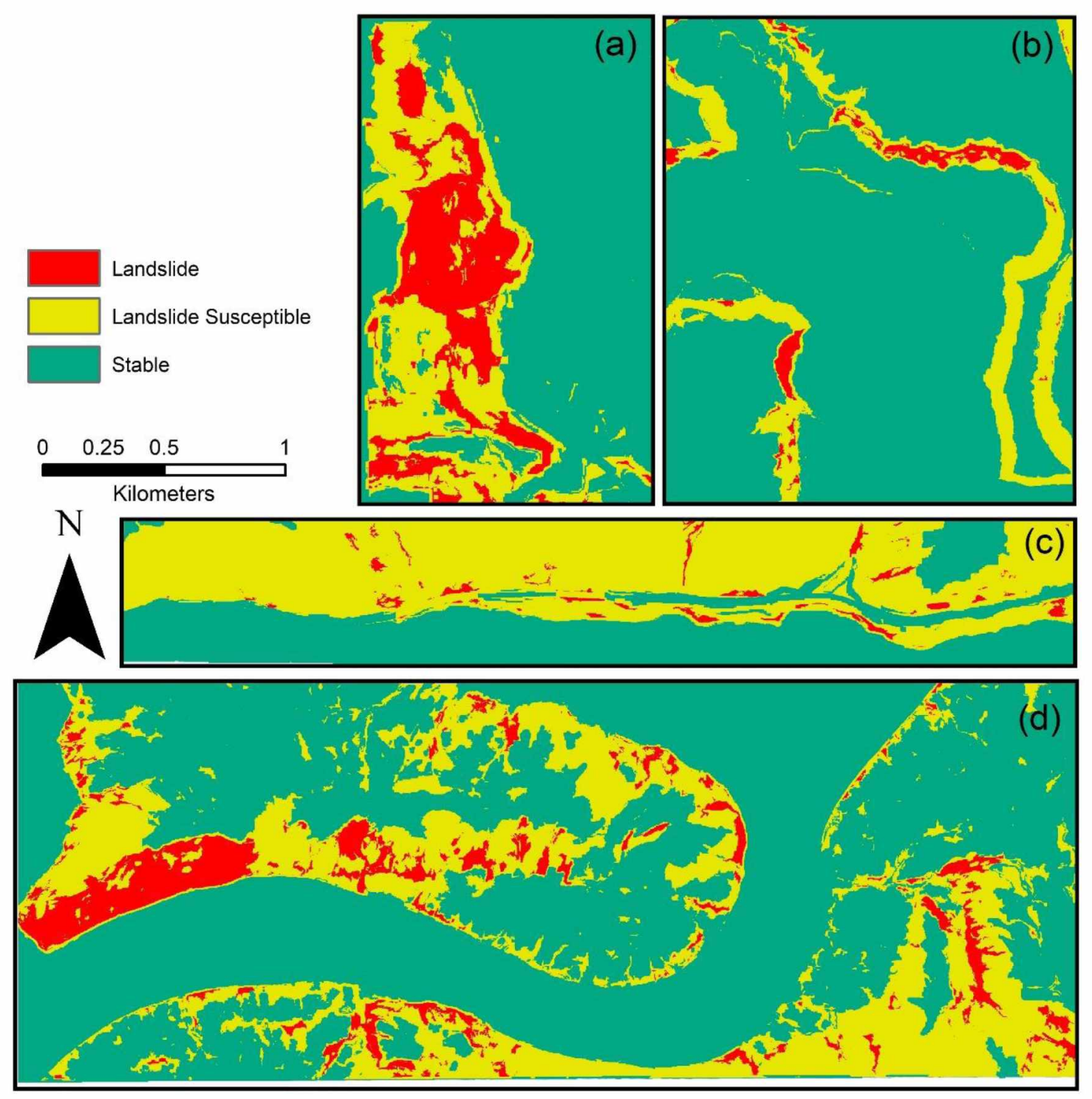

Figure 4.8: Combined classified image from $1 \mathrm{~m}, 2.5 \mathrm{~m}$, and $5 \mathrm{~m}$ resolution LiDAR data with NDVI. Study sites are (a) Slate Creek, (b) Copper River, (c) Richardson, and (d) Yukon. 
Table 4.12: Confusion matrix table for combined classified image from $1 \mathrm{~m}, 2.5 \mathrm{~m}$, and $5 \mathrm{~m}$ resolution LiDAR with NDVI

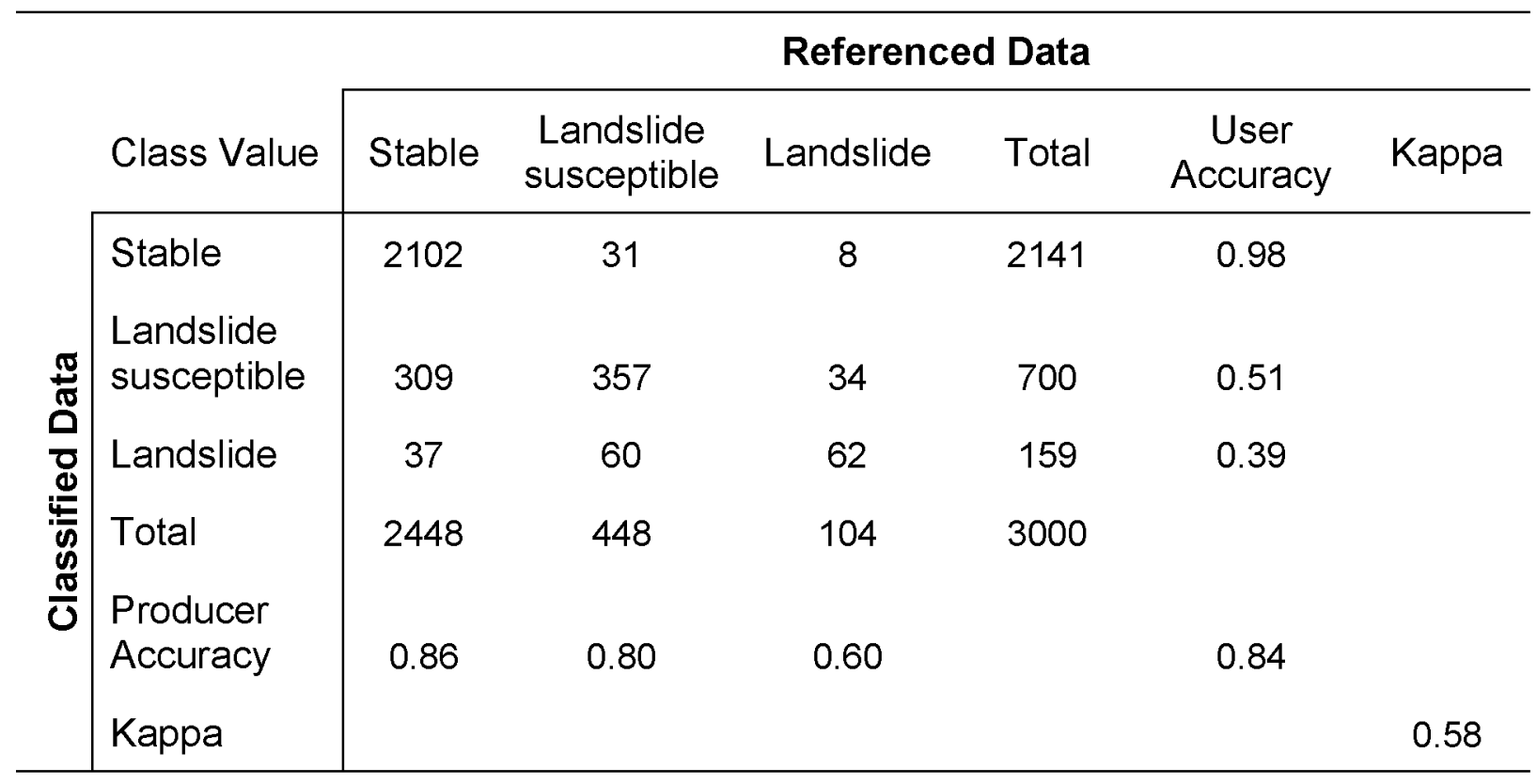



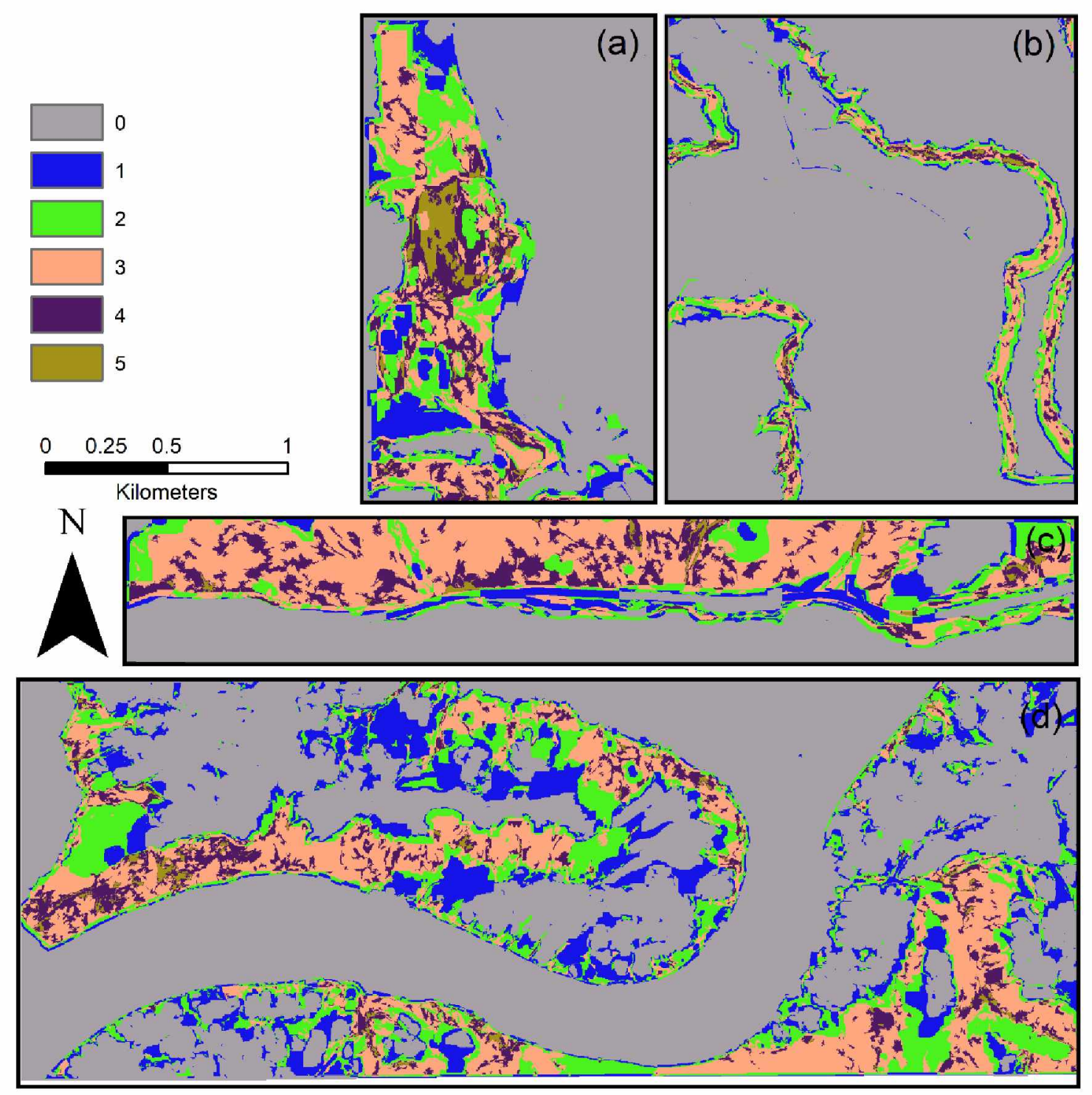

Figure 4.9: Combined map from $1 \mathrm{~m}, 2.5 \mathrm{~m}$, and $5 \mathrm{~m}$ resolution classified images without NDVI. Study sites are (a) Slate Creek, (b) Copper River, (c) Richardson, and (d) Yukon. 
has only five class values since the $5 \mathrm{~m}$ resolution map without NDVI (Fig. 4.6) does not have any landslide values. As with the previous map, I gave the landslide, landslide susceptible, and stable locations values of 2,1 , and 0 , respectively.

Again, I reclassified the combined map in Fig. 4.9 into a new map using three classes (as specified in Table 4.13), where the values 2, 1, and 0 represents landslide, landslide susceptible, and stable locations, respectively (Fig. 4.10). I conducted an accuracy assessment on the combined classified image without NDVI to generate a confusion matrix (Table 4.14).

The combined classified map from $1 \mathrm{~m}, 2.5 \mathrm{~m}$, and $5 \mathrm{~m}$ LiDAR with NDVI generated a kappa value of $58 \%$ and user accuracy of $39 \%$ for landslide locations (Table 4.12). This user accuracy is higher than for any of the individual classified maps (Tables 4.7 through 4.10). From visual inspection, the entire extent of landslide masses are identified in the combined map (Fig. 4.8), whereas in the individual maps, often only the head scarp, toe, or a smaller portion of the landslide was identified (Fig. 4.1 to Fig. 4.3).

The combined classified map from $1 \mathrm{~m}, 2.5 \mathrm{~m}$, and $5 \mathrm{~m}$ LiDAR without NDVI generated a kappa value of $53 \%$ and user accuracy of $32 \%$ for landslide locations. From visual inspection, however, this map produced a large number of false positive landslide locations, especially for the Richardson and Yukon sites (Fig. 4.10c and 4.10d). It is possible that some of the false positive landslide locations are paleolandslides. One limitation of this study is that the landslide inventory was not fieldchecked, with the exception of the Slate Creek study site and some of the landslides at the Richardson site. 
Table 4.13: Reclassified values of the combined image from Fig. 4.9

\begin{tabular}{cc}
\hline Class values in combined image & New values in the reclassified image \\
\hline 0 & 0 \\
1 & 1 \\
2 & \\
3 & 2 \\
\hline 4 & \\
\hline
\end{tabular}



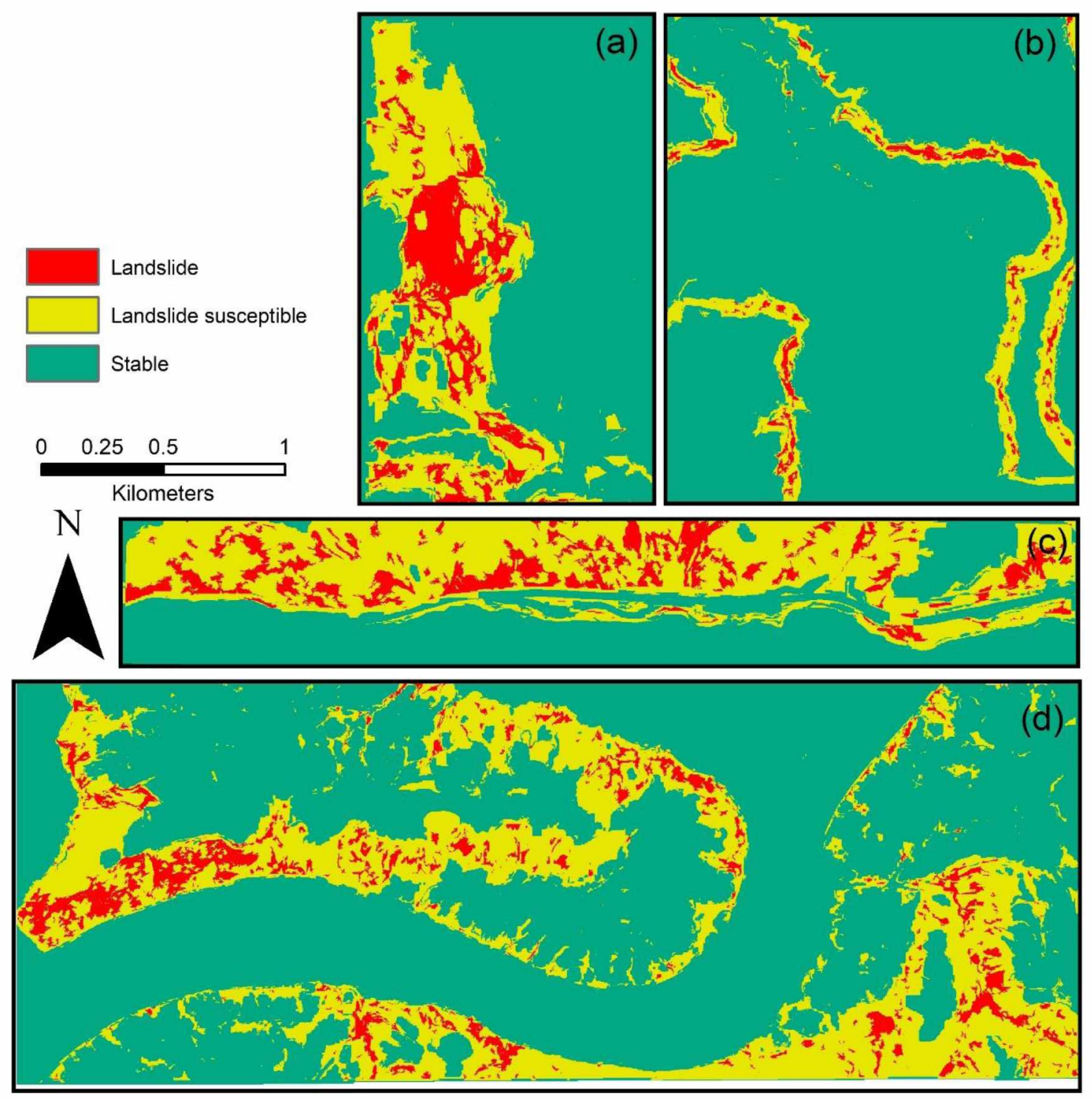

Figure 4.10: Combined classified image from $1 \mathrm{~m}, 2.5 \mathrm{~m}$, and $5 \mathrm{~m}$ resolution LiDAR data without NDVI. Study sites are (a) Slate Creek, (b) Copper River, (c) Richardson, and (d) Yukon. 
Table 4.14: Confusion matrix table for combined classified image from $1 \mathrm{~m}, 2.5 \mathrm{~m}$, and $5 \mathrm{~m}$ resolution LiDAR without NDVI

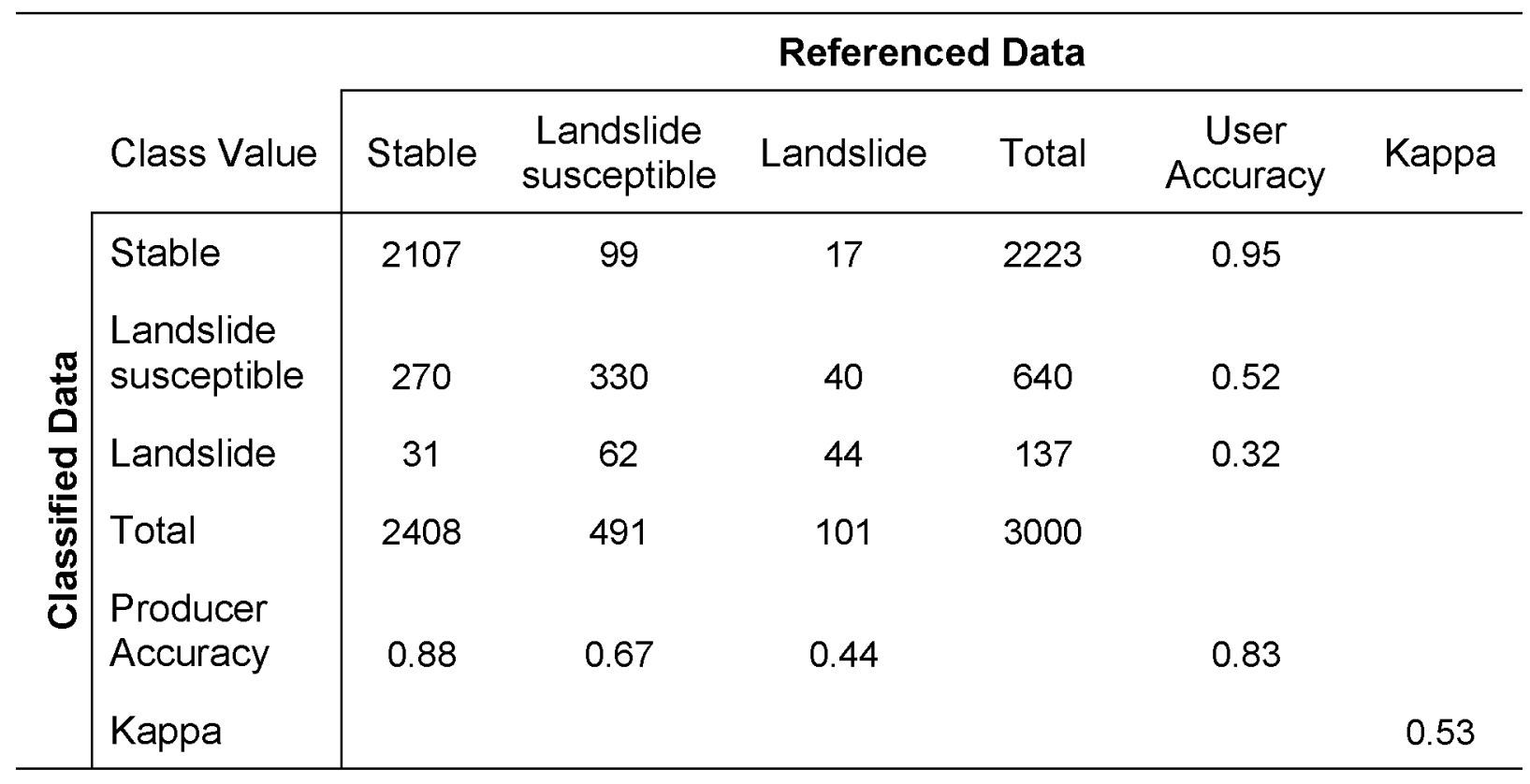


The accuracy assessment method used for the classified images is usually done for land cover classification. No standard classification procedure has yet been developed for object-oriented image classification. Since training samples were taken as objects in this study, it may have been more appropriate to generate a confusion matrix using ground-truthed objects (e.g., landslide, landslide susceptible, and stable).

While producer and user accuracy both quantify the accuracy of individual categories, the producer accuracy perhaps is more useful from a hazard management perspective. This is because the producer accuracy tells us how many ground-truthed points are correctly classified as landslides.

The roughness values depend on the method used for calculation. The method I used for roughness demonstrated extreme local relief even in the waves generated on the Yukon River surface (Fig. 3.3). Other methods may produce different results.

The spatial resolution and quality of the DEM, and color infrared imagery may affect the results of this study. Scale plays an important role in identifying landslides. From the combined classified map, it is evident that different parts of the same landslide body may be not be identifiable at different scales. This is the reason that the combined classified map gives a fuller picture, since it incorporates results from all three scales. The combined classified approach can be taken to generate landslide hazard zonation maps.

The image segmentation approach used in this study will need further development. Landslide identification using this technique depends on the minimum size of the segments. If a landslide body is smaller than the minimum segment generated from the segment mean shift function, it is possible that it would not be 
identified in subsequent phases. The spectral fingerprints of landslides and landslide susceptible locations are similar; however, the shape of the training objects helped to separate these different areas. It is important to select training samples that resemble all possible shapes in the study area. For my work, each training object included multiple different segments. The low user accuracy in identifying landslide objects can be attributed to the fact that the landslide and landslide susceptible objects both consisted of similar segments. Further study is necessary to generate a segmented image that will have more distinct segments for the landslide and landslide susceptible locations. 


\section{Chapter 5 Conclusions}

Landslide identification is important as it helps to manage this type of geohazard in a planned way. The transportation corridors in Interior Alaska have significant importance to the state's economy and transportation sector. Landslides located within these corridors may represent serious hazards to the roadways. Field identification of these landslides is often not feasible due to budget and time constraints. Hence it is important to develop an expedient and sufficiently accurate methodology that can be implemented using the limited data available. For this research, I developed a new method for landslide mapping using an object-oriented image classification approach in ArcGIS 10.5. I chose this approach since it can identify landslides rapidly using only LiDAR and color-infrared imagery.

Analysis of the results indicated that the combination of different derivatives from a LiDAR digital elevation model and the NDVI from color-infrared imagery can be used to identify landslide and landslide susceptible locations. The results also demonstrated that the scale of the LiDAR data plays an important role. The finer resolution image generated more false positives. The overall accuracy of LiDAR $1 \mathrm{~m}, 2.5 \mathrm{~m}$, and $5 \mathrm{~m}$ classified images with NDVI were $81 \%, 81 \%$, and $83 \%$, respectively. The $2.5 \mathrm{~m}$ resolution LiDAR data with NDVI performed well in identifying landslide locations compared to the other scales with a user accuracy of $32 \%$, a producer accuracy of $50 \%$, and an overall accuracy of $81 \%$. In general, the $5 \mathrm{~m}$ LiDAR with NDVI performed well in identifying landslide, landslide susceptible, and stable locations, and generated the highest kappa value of $55 \%$. 
The results indicate that image segmentation plays an important role in objectoriented image classification. Different scales of data sets identified different parts of landslides, and the combined map generated the best result in identifying each class by combining all the pixels from individual maps. The combined map with NDVI attained user accuracies of $39 \%, 51 \%$, and $98 \%$, and producer accuracies of $60 \%, 80 \%$, and $86 \%$, for landslide, landslide susceptible, and stable locations, respectively. The overall accuracy of the combined map was $84 \%$.

The method I developed for this research is fast and can be implemented easily over a large study area. It requires only LiDAR-derived products and NDVI from colorinfrared imagery. Although not as accurate, the method can be implemented even without the NDVI. It is similar to the conventional image classification approach since it is supervised; however, it eases the rigorous procedure of visually identifying individual pixels and assigning them to different classes by developing training files using large objects containing many pixels. This method can be improved, however, by fine-tuning the segmented image generation, and of course, the results should be verified through field investigations.

Because I mainly used LiDAR data, this approach relies heavily on the geomorphic expression of landslides. As a result, the age of the landslide becomes important, as the method may not easily identify paleo-landslides that have subtle surface expression. A future step to address this issue is to conduct radiometric dating of the identified landslides within the transportation corridors. Another limitation with the LiDAR data is its narrow width along the corridors; this limited the size and orientation of landslides that I was able to identify. 
I only used LiDAR-derived parameters and NDVI in this study. A suggested improvement is to include other data sets (e.g., hydrology; soil, geology, and material properties) to incorporate other environmental and geologic parameters that are important to landslide occurrence. Furthermore, in Interior Alaska, the presence of permafrost is an important parameter. Incorporating permafrost distribution and slope aspect considerations would result in a more comprehensive methodology.

This method used the 2011 LiDAR data set. Should another LiDAR data set be collected along these transportation corridors, the two digital elevation models could be differenced to determine movement that occurred between data set acquisitions. This change detection would be a desk-top approach to validate my methodology. 


\section{References}

Ahmed, B., and Dewan, A., 2017, Application of bivariate and multivariate statistical techniques in landslide susceptibility modeling in Chittagong city corporation, Bangladesh: Remote Sensing, Vol. 9, No. 4, pp. 304.

Aksoy, B., and Ercanoglu, M., 2012, Landslide identification and classification by objectbased image analysis and fuzzy logic: an example from the Azdavay region (Kastamonu, Turkey): Computers \& Geosciences, Vol. 38, No. 1, pp. 87-98.

Ballabio, C., and Sterlacchini, S., 2012, Support vector machines for landslide susceptibility mapping: the Staffora River Basin case study, Italy: Mathematical Geosciences, Vol. 44, No. 1, pp. 47-70.

Bi, R.; Schleier, M.; Rohn, J.; Ehret, D.; and Xiang, W., 2014, Landslide susceptibility analysis based on ArcGIS and artificial neural network for a large catchment in Three Gorges region, China: Environmental Earth Sciences, Vol. 72, No. 6, pp. 1925-1938.

Blaschke, T., 2010, Object based image analysis for remote sensing: ISPRS Journal of Photogrammetry and Remote Sensing, Vol. 65, No. 1, pp. 2-16.

Budimir, M. E. A.; Atkinson, P. M.; and Lewis, H. G., 2015, A systematic review of landslide probability mapping using logistic regression: Landslides, Vol. 12, No. 3, pp. $419-436$. 
Chen, W.; Ding, X.; Zhao, R.; and Shi, S., 2016, Application of frequency ratio and weights of evidence models in landslide susceptibility mapping for the Shangzhou District of Shangluo City, China: Environmental Earth Sciences, Vol. 75, No. 1, Article 64.

Choi, J.; Oh, H. J.; Lee, H. J.; Lee, C.; and Lee, S., 2012, Combining landslide susceptibility maps obtained from frequency ratio, logistic regression, and artificial neural network models using ASTER images and GIS: Engineering Geology, Vol. 124, pp. 12-23.

Congalton, R. G., 1991, A review of assessing the accuracy of classifications of remotely sensed data: Remote Sensing of Environment, Vol. 37, No. 1, pp. 3546.

Congalton, R. G.; Oderwald, R. G.; and Mead, R. A., 1983, Assessing Landsat classification accuracy using discrete multivariate analysis statistical techniques: Photogrammetric Engineering and Remote Sensing, Vol. 49, No. 12, pp. 1671 1678.

Cruden, D. M., 1991, A simple definition of a landslide: Bulletin of the International Association of Engineering Geology, Vol. 43, pp. 27-29.

Dahal, R. K., 2014, Regional-scale landslide activity and landslide susceptibility zonation in the Nepal Himalaya: Environmental Earth Sciences, Vol. 71, No. 12, pp. 5145-5164. 
Devkota, K. C.; Regmi, A. D.; Pourghasemi, H. R.; Yoshida, K.; Pradhan, B.; Ryu, I. C.; Dhital, M. R.; and Althuwaynee, O. F., 2013, Landslide susceptibility mapping using certainty factor, index of entropy and logistic regression models in GIS and their comparison at Mugling-Narayanghat road section in Nepal Himalaya: Natural Hazards, Vol. 65, No. 1, pp. 135-165.

Dieu Tien, B.; Lofman, O.; Revhaug, I.; and Dick, O., 2011, Landslide susceptibility analysis in the Hoa Binh Province of Vietnam using statistical index and logistic regression: Natural Hazards, Vol. 59, No. 3, pp. 1413-1444.

Dou, J.; Yamagishi, H.; Pourghasemi, H. R.; Yunus, A. P.; Song, X.; Xu, Y.; and Zhu, Z., 2015, An integrated artificial neural network model for the landslide susceptibility assessment of Osado Island, Japan: Natural Hazards, Vol. 78, No. 3, pp. 17491776.

Drăguţ, L., and Blaschke, T., 2006, Automated classification of landform elements using object-based image analysis: Geomorphology, Vol. 81, No. 3, pp. 330-344.

Drăguţ, L.; Eisank, C.; and Strasser, T., 2011, Local variance for multi-scale analysis in geomorphometry: Geomorphology, Vol. 130, No. 3-4, pp. 162-172.

Environmental Systems Research Institute (ESRI), 2017, ArcGIS Desktop Release 10.5: Redlands, CA.

Falaschi, F.; Giacomelli, F.; Federici, P.R.; Puccinelli, A.; D'Amato Avanzi, G.; Pochini, A.; and Ribolini, A., 2009, Logistic regression versus artificial neural networks; landslide susceptibility evaluation in a sample area of the Serchio River valley, Italy: Natural Hazards, Vol. 50, No. 3, pp. 551-569. 
Felicisimo, A. M.; Cuartero, A.; Remondo, J.; and Quiros, E., 2013, Mapping landslide susceptibility with logistic regression, multiple adaptive regression splines, classification and regression trees, and maximum entropy methods; a comparative study: Landslides, Vol. 10, No. 2, pp. 175-189.

Ferrians, O. J., Jr.; Nichols, D. R.; and Williams, J. R., 1983, Copper River Basin. In Péwé, T. L., and Reger, R. D. (Editors), Guidebook to Permafrost and Quaternary Geology along the Richardson and Glenn Highways, between Fairbanks and Anchorage, Alaska: Alaska Division of Geological \& Geophysical Surveys Guidebook 1, pp. 39-44.

Fiorucci, F.; Cardinali, M.; Carla, R.; Rossi, M.; Mondini, A.C.; Santurri, L.; Ardizzone, F.; and Guzzetti, F., 2011, Seasonal landslide mapping and estimation of landslide mobilization rates using aerial and satellite images: Geomorphology, Vol. 129 , No. 1-2, pp. 59-70.

Gelisli, K.; Kaya, T.; and Babacan, A. E., 2015, Assessing the factor of safety using an artificial neural network; case studies on landslides in Giresun, Turkey: Environmental Earth Sciences, Vol. 73, No. 12, pp. 8639-8646.

Grohmann, C. H.; Smith, M. J.; and Riccomini, C., 2011, Multiscale analysis of topographic surface roughness in the Midland Valley, Scotland: IEEE Transactions on Geoscience and Remote Sensing, Vol. 49, No. 4, pp. $1200-$ 1213. 
Guzzetti, F.; Carrara, A.; Cardinali, M.; and Reichenbach, P., 1999, Landslide hazard evaluation: a review of current techniques and their application in a multi-scale study, Central Italy: Geomorphology, Vol. 31, No. 1-4, pp. 181-216.

Guzzetti, F.; Mondini, A.C.; Cardinali, M.; Fiorucci, F.; Santangelo, M.; and Chang, K.T., 2012, Landslide inventory maps: New tools for an old problem. Earth-Science Reviews, Vol. 112, No. 1-2, pp. 42-66.

Hong, H.; Pradhan, B.; Jebur, M. N.; Bui, D. T.; Xu, C.; and Akgun, A., 2016, Spatial prediction of landslide hazard at the Luxi area (China) using support vector machines: Environmental Earth Sciences, Vol. 75, No. 1, pp. 1-14.

Hubbard, T. D.; Koehler, R. D.; and Combellick, R. A., 2011, High-resolution Lidar Data for Alaska Infrastructure Corridors: Alaska Division of Geological \& Geophysical Surveys Raw Data File 2011-3, 291 p., http://doi.org/10.14509/22722

Jenness, J. S., 2004, Calculating landscape surface area from digital elevation models: Wildlife Society Bulletin, Vol. 32, No. 3, pp. 829-839.

Kasai, M.; Ikeda, M.; Asahina, T.; and Fujisawa, K., 2009, LiDAR-derived DEM evaluation of deep-seated landslides in a steep and rocky region of Japan: Geomorphology, Vol. 113, No. 1, pp. 57-69.

Kavzoglu, T.; Sahin, E.K.; and Colkesen, I., 2014, Landslide susceptibility mapping using GIS-based multi-criteria decision analysis, support vector machines, and logistic regression: Landslides, Vol. 11, No. 3, pp. 425-439. 
Koehler, R.D., 2011, Application of lidar to mapping geologic hazards along gas pipelines in Alaska (poster): Geological Society of America Abstracts with Programs, Vol. 43, No. 4, p. 83, Paper No. 30-2; Alaska Division of Geological \& Geophysical Surveys, 1 sheet. http://doi.org/10.14509/22623

Koehler, R.D.; Reger, R.D.; Sicard, K.R.; and Spangler, E.R., 2013, Yukon River bridge landslide: preliminary geologic and geotechnical evaluation: Alaska Division of Geological \& Geophysical Surveys Preliminary Interpretive Report 2013-6, pp. 69. http://doi.org/10.14509/25642

Kumar, R., and Anbalagan, R., 2015, Landslide susceptibility zonation in part of Tehri reservoir region using frequency ratio, fuzzy logic and GIS: Journal of Earth System Science, Vol. 124, No. 2, pp. 431-448.

Lee, M. J.; Choi, J. W.; Oh, H. J.; Won, J. S.; Park, I.; and Lee, S., 2012, Ensemblebased landslide susceptibility maps in Jinbu area, Korea: Environmental Earth Sciences, Vol. 67, No. 1, pp. 23-37.

Lee, S., and Pradhan, B., 2007, Landslide hazard mapping at Selangor, Malaysia using frequency ratio and logistic regression models: Landslides, Vol. 4, No. 1, pp. 3341.

Lee, S.; Ryu, J. H.; Won, J. S.; and Park, H. J., 2004, Determination and application of the weights for landslide susceptibility mapping using an artificial neural network: Engineering Geology, Vol. 71, No. 3-4, pp. 289-302. 
Lee, S., and Sambath, T., 2006, Landslide susceptibility mapping in the Damrei Romel area, Cambodia using frequency ratio and logistic regression models: Environmental Geology, Vol. 50, No. 6, pp. 847-855.

Leshchinsky, B. A.; Olsen, M. J.; and Tanyu, B. F., 2015, Contour connection method for automated identification and classification of landslide deposits: Computers \& Geosciences, Vol. 74, pp. 27-38.

Li, X.; Cheng, X.; Chen, W.; Chen, G.; and Liu, S., 2015, Identification of forested landslides using lidar data, object-based image analysis, and machine learning algorithms: Remote Sensing, Vol. 7, No. 8, pp. 9705-9726.

Li, Y.; Chen, G.; Tang, C.; Zhou, G.; and Zheng, L., 2012, Rainfall and earthquakeinduced landslide susceptibility assessment using GIS and artificial neural network: Natural Hazards and Earth System Sciences, Vol. 12, No. 8, pp. 27192729 .

Marjanović, M.; Kovačević, M.; Bajat, B.; and Voženílek, V., 2011, Landslide susceptibility assessment using SVM machine learning algorithm: Engineering Geology, Vol. 123, No. 3, pp. 225-234.

Martha, T. R.; Kerle, N.; Jetten, V.; van Westen, C. J.; and Kumar, K. V., 2010, Characterizing spectral, spatial and morphometric properties of landslides for semi-automatic detection using object-oriented methods: Geomorphology, Vol. 116, No. 1, pp. 24-36. 
Massey, C.; Townsend, D.; Rathje, E.; Allstadt, K.E.; Lukovic, B.; Kaneko, Y.; Bradley, B.; Wartman, J.; Jibson, R. W.; Petley, D. N.; and Horspool, N., 2018, Landslides triggered by the 14 November 2016 Mw 7.8 Kaikōura Earthquake, New Zealand. Bulletin of the Seismological Society of America. doi:

\section{https://doi.org/10.1785/0120170305}

Micheletti, N.; Foresti, L.; Robert, S.; Leuenberger, M.; Pedrazzini, A.; Jaboyedoff, M.; and Kanevski, M., 2014, Machine learning feature selection methods for landslide susceptibility mapping: Mathematical Geosciences, Vol. 46, No. 1, pp. $33-57$.

Mohammady, M.; Pourghasemi, H. R.; and Pradhan, B., 2012, Landslide susceptibility mapping at Golestan Province, Iran: a comparison between frequency ratio, Dempster-Shafer, and weights-of-evidence models: Journal of Asian Earth Sciences, Vol. 61, pp. 221-236.

Moosavi, V.; Talebi, A.; and Shirmohammadi, B., 2014, Producing a landslide inventory map using pixel-based and object-oriented approaches optimized by Taguchi method: Geomorphology, Vol. 204, pp. 646-656.

Neuhäuser, B., and Terhorst, B., 2007, Landslide susceptibility assessment using "weights-of-evidence" applied to a study area at the Jurassic escarpment (SWGermany): Geomorphology, Vol. 86, No. 1, pp. 12-24. 
Nourani, V.; Pradhan, B.; Ghaffari, H.; and Sharifi, S. S., 2014, Landslide susceptibility mapping at Zonouz Plain, Iran using genetic programming and comparison with frequency ratio, logistic regression, and artificial neural network models: Natural Hazards, Vol. 71, No. 1, pp. 523-547.

Ozdemir, A., and Altural, T., 2013, A comparative study of frequency ratio, weights of evidence and logistic regression methods for landslide susceptibility mapping: Sultan Mountains, SW Turkey: Journal of Asian Earth Sciences, Vol. 64, pp. 180197.

Paul, R., and Hussain, Z., 2017, Landslide, floods kill 156 in Bangladesh, India; toll could rise: Reuters, Electronic document available at https://www.reuters.com/article/us-bangladesh-landslides/landslide-floods-kill156-in-bangladesh-india-toll-could-rise-idUSKBN1950AI

Pourghasemi, H. R.; Moradi, H. R.; Fatemi Aghda, S. M.; Sezer, E. A.; Goli Jirandeh, A.; and Pradhan, B., 2014, Assessment of fractal dimension and geometrical characteristics of the landslides identified in north of Tehran, Iran: Environmental Earth Sciences, Vol. 71, No. 8, pp. 3617-3626.

Pradhan, B., 2013, A comparative study on the predictive ability of the decision tree, support vector machine and neuro-fuzzy models in landslide susceptibility mapping using GIS: Computers \& Geosciences, Vol. 51, pp. 350-365.

Pradhan, B., and Lee, S., 2009, Regional landslide susceptibility analysis using backpropagation neural network model at Cameron Highland, Malaysia: Landslides, Vol. 7 , No. 1, pp. 13-30. 
Ramesh, V., and Anbazhagan, S., 2015, Landslide susceptibility mapping along Kolli Hills Ghat road section (India) using frequency ratio, relative effect and fuzzy logic models: Environmental Earth Sciences, Vol. 73, No. 12, pp. 8009-8021.

Reger, R.D., and Solie, D.N., 2008, Reconnaissance interpretive map of permafrost, Alaska Highway Corridor, Delta Junction to Dot Lake, Alaska: Alaska Division of Geological \& Geophysical Surveys Preliminary Interpretive Report 2008-3c, 10 p., 2 sheets, scale $1: 63,360$.

Reger, R.D.; Stevens, D.S.P.; and Solie, D.N., 2008, Surficial-geologic map, Delta Junction to Dot Lake, Alaska Highway corridor: Alaska Division of Geological \& Geophysical Surveys Preliminary Interpretive Report 2008-3A, 48 p., 2 sheets, scale 1:63,360. http://doi.org/10.14509/17961

Regmi, N. R.; Giardino, J. R.; McDonald, E. V.; and Vitek, J. D., 2014, A comparison of logistic regression-based models of susceptibility to landslides in western Colorado, USA: Landslides, Vol. 11, No. 2, pp. 247-262.

Regmi, N. R.; Giardino, J. R.; and Vitek, J. D., 2010, Modeling susceptibility to landslides using the weight of evidence approach: Western Colorado, USA: Geomorphology, Vol. 115, No. 1, pp. 172-187.

Samodra, G.; Chen, G.; Sartohadi, J.; and Kasama, K., 2017, Comparing data-driven landslide susceptibility models based on participatory landslide inventory mapping in Purwosari area, Yogyakarta, Java: Environmental Earth Sciences, Vol. 76, No. 4, pp. 184. 
Son, J.; Suh, J.; and Park, H. D., 2016, GIS-based landslide susceptibility assessment in Seoul, South Korea, applying the radius of influence to frequency ratio analysis: Environmental Earth Sciences, Vol. 75, No. 4, Article 310.

Story, M., and Congalton, R. G., 1986, Accuracy assessment: a user's perspective: Photogrammetric Engineering and Remote Sensing, Vol. 52, No. 3, pp. 397-399.

Su, C.; Wang, L.; Wang, X.; Huang, Z.; and Zhang, X., 2015, Mapping of rainfallinduced landslide susceptibility in Wencheng, China, using support vector machine: Natural Hazards, Vol. 76, No. 3, pp. 1759-1779.

Tsangaratos, P., and Benardos, A., 2014, Estimating landslide susceptibility through a artificial neural network classifier: Natural Hazards, Vol. 74, No. 3, pp. 14891516.

Van Den Eeckhaut, M.; Kerle, N.; Poesen, J.; and Hervás, J., 2012, Object-oriented identification of forested landslides with derivatives of single pulse LiDAR data: Geomorphology, Vol. 173, pp. 30-42.

Van Westen, C. J.; Rengers, N.; and Soeters, R., 2003, Use of geomorphological information in indirect landslide susceptibility assessment: Natural Hazards, Vol. 30, No. 3, pp. 399-419.

Vapnik, V. N., 1995, The Nature of Statistical Learning Theory: Springer-Verlag, Berlin, Germany, 188 p.

Varnes, D.J., 1978, Slope Movement Types and Processes: Special Report Transportation Research Board, National Research Council, Vol. 176, pp. 11-33. 
Wahrhaftig, C., 1965. Physiographic divisions of Alaska: Geological Survey Professional Paper 482, US Government Printing Office, Washington, 52 p.

Wahrhaftig, C., 1970, Geologic Map of the Healy D-5 Quadrangle, Alaska: U.S. Geological Survey Geologic Quadrangle Map 804, 1 sheet, scale 1:63,360.

Wahrhaftig, C., and Black, R.F., 1958, Quaternary Geology of the Nenana River Valley and Adjacent Parts of the Alaska Range: U.S. Geological Survey Professional Paper 293, pp. 1-78.

Wartman, J.; Montgomery, D. R.; Anderson, S. A.; Keaton, J. R.; Benoit, J.; dela Chapelle, J.; and Gilbert, R., 2016, The 22 March 2014 Oso Landslide, Washington, USA: Geomorphology, Vol. 253, pp. 275-288.

Weber, F. R.; Wheeler, K. L.; Rinehart, C. D.; Chapman, R. M.; and Blodgett, R. B., 1992, Geologic Map of the Livengood Quadrangle, Alaska: U.S. Geological Survey Open-File Report 92-562, 20 p., 1 sheet, scale 1:250,000.

Wiedmer, M.; Montgomery, D. R.; Gillespie, A. R.; and Greenberg, H., 2010, Late Quaternary megafloods from Glacial Lake Atna, Southcentral Alaska, U.S.A.: Quaternary Research, Vol. 73, No. 3, pp. 413-424.

Wilson, F. H.; Hults, C. P.; Mull, C. G.; and Karl, S. M., 2015, Geologic Map of Alaska: U.S. Geological Survey Scientific Investigations Map SIM 3340.

Witze, A., 2014, Afghan landslide was 'an accident waiting to happen': Nature; Electronic document, available at http://www.nature.com/news/afghan-landslidewas-anaccident-waiting-to-happen-1.15158 
Wu, X.; Ren, F.; and Niu, R., 2014, Landslide susceptibility assessment using object mapping units, decision tree, and support vector machine models in the Three Gorges of China: Environmental Earth Sciences, Vol. 71, No. 11, pp. 4725-4738.

Xu, C.; Dai, F.; Xu, X.; and Lee, Y. H., 2012. GIS-based support vector machine modeling of earthquake-triggered landslide susceptibility in the Jianjiang River watershed, China: Geomorphology, Vol. 145, pp. 70-80.

Xu, C.; Shen, L.; and Wang, G., 2016, Soft computing in assessment of earthquaketriggered landslide susceptibility: Environmental Earth Sciences, Vol. 75, No. 9 , Article 767.

Xu, C.; Xu, X.; Dai, F.; Wu, Z.; He, H.; Shi, F.; Wu, X.; and Xu, S., 2013, Application of an incomplete landslide inventory, logistic regression model and its validation for landslide susceptibility mapping related to the May 12, 2008 Wenchuan earthquake of China: Natural Hazards, Vol. 68, No. 2, pp. 883-900.

Yao, X.; Tham, L. G.; and Dai, F. C. 2008, Landslide susceptibility mapping based on support vector machine: a case study on natural slopes of Hong Kong, China: Geomorphology, Vol. 101, No. 4, pp. 572-582.

Yilmaz, I., 2009, Landslide susceptibility mapping using frequency ratio, logistic regression, artificial neural networks and their comparison: a case study from Kat landslides (Tokat-Turkey): Computers \& Geosciences, Vol. 35, No. 6, pp. 11251138. 
Youssef, A. M.; Pradhan, B.; Pourghasemi, H. R.; and Abdullahi, S., 2015, Landslide susceptibility assessment at Wadi Jawrah Basin, Jizan region, Saudi Arabia using two bivariate models in GIS: Geosciences Journal, Vol. 19, No. 3, pp. 449469.

Zhang, M.; Cao, X.; Peng, L.; and Niu, R., 2016a, Landslide susceptibility mapping based on global and local logistic regression models in Three Gorges Reservoir area, China: Environmental Earth Sciences, Vol. 75, No. 11, Article 958.

Zhang, Z.; Yang, F.; Chen, H.; Wu, Y.; Li, T.; Li, W.; Wang, Q.; and Liu, P., 2016b, GISbased landslide susceptibility analysis using frequency ratio and evidential belief function models: Environmental Earth Sciences, Vol. 75, No. 11, Article 948. 